\title{
Photocatalytic fabrics based on reduced graphene oxide and $\mathrm{TiO}_{2}$ coatings
}

\author{
J. Molina ${ }^{\mathrm{a}, \mathrm{b}}$, F. Fernandes ${ }^{\mathrm{c}}$, J. Fernández ${ }^{\mathrm{a}}$, M. Pastor ${ }^{\mathrm{c}}$, A. Correia $^{\mathrm{c}}$, A.P. Souto ${ }^{\mathrm{b}}$, \\ J.O. Carneiro ${ }^{c}$, V. Teixeira ${ }^{c}$, F. Cases ${ }^{a, *}$ \\ a Departamento de Ingeniería Textil y Papelera, EPS de Alcoy, Universitat Politècnica de València, Plaza Ferrándiz y Carbonell s/n, 03801 Alcoy, Spain \\ b Department of Textile Engineering, University of Minho, Azurém Campus, 4800-058 Guimarães, Portugal \\ ' Department Physics, University of Minho, Azurém Campus, 4800-058 Guimarães, Portugal
}

\section{A R T I C L E I N F O}

\section{Article history:}

Received 26 January 2015

Received in revised form 4 April 2015

Accepted 18 April 2015

Available online 23 May 2015

\section{Keywords:}

Reduced graphene oxide

Titanium dioxide

Fabrics

Scanning electrochemical microscopy

Photocatalysis

Rhodamine B

\begin{abstract}
A B S T R A C T
The purpose of this work is to obtain photocatalytic fabrics based on reduced graphene oxide (RGO) and $\mathrm{TiO}_{2}$ coatings on polyester fabrics. The influence of the applied number of RGO coatings on properties such as light absorption, conductivity, electroactivity and photocatalytic properties of the fabrics was established. An improvement of these properties with the number of RGO coatings applied was obtained. FESEM, EDX, XPS and FTIR-ATR showed the incorporation of the $\mathrm{TiO}_{2}$ nanoparticles on the fabrics. FTIR-ATR showed the formation of a bidentate carboxylic ligand with titanium atoms. The photocatalytic properties of the fabrics were tested with Rhodamine B dye solutions. Photocatalytic efficiency increased with the number of RGO coatings, due to the increased light absorption, and better electrical properties. The charge transfer resistance $\left(R_{\mathrm{ct}}\right)$ and its time constant $(\tau)$ decreased, indicating a better electron transfer which helps to increase the lifetime of the pair electron/hole.
\end{abstract}

(C) 2015 Elsevier B.V. All rights reserved.

\section{Introduction}

The development of fabrics with new properties and functionalities has received a great deal of interest during the last years. Different properties such as electrical conduction [1], flame resistance [2], self-cleaning [3], thermal regulation [4], color change [5], solar energy production [6], photonic [7], antimicrobial [8], UV protecting [9] or even catalysis [10] have been reported on textiles.

On the other hand, the family of graphene materials has emerged as revolutionary materials in the field of physics and materials science due to its electronic, mechanical, optical or thermal properties that open the door to a range of different applications [11-18].

In the field of catalysis, the combination of graphene and its derivatives with semiconductors (such as $\mathrm{TiO}_{2}$ ) has emerged as an interesting approach to increase the lifetime of the pair

\footnotetext{
* Corresponding author. Tel.: +34 966528412; fax: +34 966528438.

E-mail addresses: jamopue@doctor.upv.es (J. Molina),b6073@fisica.uminho.pt (F. Fernandes), jaferse1@posgrado.upv.es (J. Fernández),

marianapastor88@gmail.com (M. Pastor), anacamcorreia@gmail.com (A. Correia), souto@det.uminho.pt (A.P. Souto), carneiro@fisica.uminho.pt (J.O. Carneiro), vasco@fisica.uminho.pt (V. Teixeira),fjcases@txp.upv.es (F. Cases).
}

electron/hole, which increases the efficiency of the catalytic systems [19-22]. Graphene can serve as a conductor and electrons are transferred from the conduction band of $\mathrm{TiO}_{2}$ to graphene sheets, this difficulties the recombination of the pair electron/hole and increases the lifetime of the pair. Moreover, the efficiency of the system is increased by a greater generation of radicals. Other benefit of employing graphene and its derivatives is the great adsorption capacity of organic molecules, which allows a better contact between the pollutants and the catalytic surface area. Another plus that has been observed is an increased absorption in the spectral range due to an increased band-gap of $\mathrm{TiO}_{2}$ arising from the interaction with graphene derivatives. Several studies have focused on the employment of graphene and $\mathrm{TiO}_{2}$ in heterogeneous photocatalysis [23-33]. Different graphene derivatives have been employed, such as: graphene oxide [22-24], reduced graphene oxide [26-31] or graphene [32,33]. Graphene oxide itself also presents photocatalytic properties [34-36]. The gas-phase catalytic degradation of pollutants has also been reported for graphene- $\mathrm{TiO}_{2}$ nanocomposites [37]. Different strategies have been employed to improve the efficiency of the catalysts; such as: the employment of metal ions embedded between graphene and semiconductors which act as charge carriers and enhance the charge separation process [38], the improvement of the interfacial contact between graphene and the photocatalyst [39], the use of Pd nanoparticles that act as mediator 
in the interfacial charge transfer between the catalyst and graphene [40]. When employing RGO, which has lower conductivity due to the presence of defects that cannot be removed after reduction, the use of Ag nanowires has been reported as a method to enhance the charge transfer pathways [41].

Fabrics are materials with high surface area that can serve as support for the deposition of active materials. They are also versatile and can be bended to adopt different forms. The advantage of these fabrics is that the catalyst can be deposited on the fabric and can be easily recovered from solution. Traditional photocatalysts that are dispersed in solution have the disadvantage that after reaction, the catalyst has to be recovered through centrifugation. The catalytic activity is affected by the recycling due to aggregation or incomplete separation from the solution [42].

Different papers have employed photocatalytic materials to produce self-cleaning fabrics, such as: $\mathrm{TiO}_{2}$ [43-45], $\mathrm{Au} / \mathrm{TiO}_{2}$ [46], $\mathrm{SiO}_{2} / \mathrm{TiO}_{2}$ [47] or $\mathrm{TiO}_{2} / \mathrm{AgI}$ [48]. The employment of graphene/ $/ \mathrm{TiO}_{2}$ nanocomposites applied on fabrics has also been recently reported and has shown its advantages [49,50].

In the present paper, the combination of $\mathrm{TiO}_{2}$ and $\mathrm{RGO}$ to produce photocatalytic fabrics is studied. A plasma treatment and a bovine serum albumin coating were applied to increase the fixation and homogeneity of the RGO coatings [51]. GO was reduced to RGO chemically and different number of RGO coatings was applied to improve the conductivity of the fabrics. Thereafter, $\mathrm{TiO}_{2}$ nanoparticles were deposited by immersion of the RGO-coated fabrics in a $\mathrm{TiO}_{2}$ solution. An electrochemical approach (not employed in bibliography to test these materials) has been employed to study the influence of the conductivity and the electrochemical properties (such as charge transfer resistance and time constant) of the graphene-coated fabrics on the photocatalytic properties of the fabrics. The photocatalytic properties of the fabrics were tested with the degradation of Rhodamine B solutions.

\section{Experimental}

\subsection{Reagents and materials}

All reagents employed were of analytical grade.

For the synthesis: monolayer graphene oxide (GO) powders were acquired from Nanoinnova Technologies S.L. (Spain). Sodium dithionite $\left(\mathrm{Na}_{2} \mathrm{~S}_{2} \mathrm{O}_{4}\right)$ was acquired from Merck. Bovine serum albumin (BSA) was purchased from Sigma Aldrich. Commercial $\mathrm{TiO}_{2}$ nanoparticles were acquired from Quimidroga S.A. and consisted of a mixture of the anatase (80\%) and rutile (20\%) crystalline phases. Setamol BL was acquired from BASF.

Polyester (PES) fabrics characteristics were: fabric surface density, $100 \mathrm{~g} \mathrm{~m}^{-2}$; warp threads per cm, 55; weft threads per $\mathrm{cm}, 29$. These are specific terms used in the field of textile industry and their meaning can be consulted in a textile glossary [52].

For the characterization: sulphuric acid $\left(\mathrm{H}_{2} \mathrm{SO}_{4}\right)$ and potassium chloride $(\mathrm{KCl})$ were purchased from Merck. $\mathrm{K}_{4} \mathrm{Fe}(\mathrm{CN})_{6} 99 \%$ was used as received from Acrōs Organics. Rhodamine B was supplied by Sigma Aldrich.

When needed, solutions were deoxygenated by bubbling nitrogen $\left(\mathrm{N}_{2}\right.$ premier $\left.\mathrm{X} 50 \mathrm{~S}\right)$. Ultrapure water was obtained from an Elix 3 Millipore-Milli-Q Advantage A10 system with a resistivity near to $18.2 \mathrm{M} \Omega \mathrm{cm}$.

\subsection{Dielectric barrier discharge (DBD) treatment}

Dielectric barrier discharge modality (DBD) at atmospheric pressure (Softal/University of Minho patented prototype) was employed to carry out the plasma treatment of polyester fabrics [53]. The width of the laboratorial prototype machine used in this work was $50 \mathrm{~cm}$ and consisted of the following components: a metallic electrode coated with ceramic, a metallic counter electrode coated with silicone, an electric generator and a high tension transformer. The power $(P)$, velocity $(v)$ and $(N)$ are control parameters, where $N$ is the number of passages of the fabric through the electrodes to achieve the desired plasma dosage. The plasma dosage is defined by the following Eq. (1) [53]:

Dosage $=\frac{N \cdot P}{v \cdot W}$

where $N$ (number of passages), $P$ (power, $W$ ), $v$ (velocity, $\mathrm{m} \mathrm{min}^{-1}$ ), $w$ (width, $0.5 \mathrm{~m}$ ). For the treatment of polyester fabrics, a velocity of $4 \mathrm{~m} \mathrm{~min}^{-1}$ was employed, the power employed was $1000 \mathrm{~W}$ and 6 passages were used. The plasma dosage applied was $3000 \mathrm{~W} \mathrm{~min} \mathrm{~m}^{-2}$ and it was previously optimized [51].

\subsection{Synthesis of reduced graphene oxide on polyester fabrics}

The plasma treatment generates negative charges on the surface of polyester fabrics (hydroxyl, carbonyl and carboxyl groups are created) [54]. GO also presents negative charges so the deposition of $\mathrm{GO}$ on the fabrics is not possible in these conditions since electrostatic repulsion does not allow it. This is why bovine serum albumin (BSA) was employed as an intermediate coating that acquired positive charge and allowed the deposition of GO on the surface of the fabrics. A $0.5 \%$ weight BSA solution [55] was employed to coat the plasma treated PES samples. Fabrics were put in contact with the BSA solution during $10 \mathrm{~min}$ to allow its adsorption, after this time fabrics were rinsed with water the remove the BSA's excess.

PES-plasma-BSA fabrics were coated with reduced graphene oxide (RGO) similarly to Fugetsu et al. [56]. A $3 \mathrm{~g} \mathrm{~L}^{-1}$ GO solution was obtained placing GO monolayer powders in an ultrasound bath for $60 \mathrm{~min}$. The first stage of the synthesis was carried out by putting in contact the GO solution with the fabric to allow the adsorption of GO sheets on the surface of the fabrics. This stage lasted $1 \mathrm{~h}$. After this time, fabrics with GO were dried under room conditions. The second stage of the synthesis was the reduction of GO to RGO. Fabrics coated with GO were placed for $30 \mathrm{~min}$ in a solution containing the reducer $\left(50 \mathrm{mM} \mathrm{Na}_{2} \mathrm{~S}_{2} \mathrm{O}_{4}\right)$ at approximately $90^{\circ} \mathrm{C}$. Samples with a different number of RGO coatings (1-4) were obtained (PES-1G to PES-4G) repeating the procedure mentioned above.

\subsection{Dispersion of $\mathrm{TiO}_{2}$ on the PES-RGO fabrics}

A solution of $5 \mathrm{~g} \mathrm{~L}^{-1}(500 \mathrm{~mL})$ of $\mathrm{TiO}_{2}$ nanoparticles was prepared in water. An anionic surfactant was added (Setamol BL) (1 mL) to increase the fixation of $\mathrm{TiO}_{2}$ nanoparticles on the fabrics. The solution was stirred during $5 \mathrm{~min}$. After this time, the PES-RGO fabrics were put in contact and stirred with the solution during $2 \mathrm{~min}$. After this, the fabrics were padded two times at 2-bar pressure and finally dried in an oven at $100^{\circ} \mathrm{C}$.

\subsection{Atomic force microscopy (AFM)}

Atomic force microscopy (AFM) was used to evaluate surface topography and roughness of the different samples. AFM analyses were performed with a multimode AFM microscope with a Nanoscope ${ }^{\circledR}$ IIIa ADCS controller (Veeco Metrology Group). A monolithic silicon cantilever (FESP, tip radius $8 \mathrm{~nm}$, Bruker AFM probes) with a constant force of $2.8 \mathrm{~N} / \mathrm{m}$ and a resonance frequency of $75 \mathrm{kHz}$ was used to work on tapping mode. 


\subsection{Field emission scanning electron microscopy (FESEM) and energy dispersive $\mathrm{X}$-ray (EDX)}

A Zeiss Ultra 55 FESEM was used to observe the morphology of the samples using an acceleration voltage of $3 \mathrm{kV}$. Energy dispersive $\mathrm{X}$-ray (EDX) measurements were performed between 0 and $10 \mathrm{kV}$.

\section{7. $X$-ray diffraction $(X R D)$}

The XRD patterns of some samples $\left(\mathrm{TiO}_{2}\right.$, PES, PES-4G and PES$4 \mathrm{G}+\mathrm{TiO}_{2}$ ) were acquired in the range of $20^{\circ}-90^{\circ}(2 \theta)$ using a Bruker D8 Discover X-ray diffractometer with the conventional Bragg-Brentano geometry.

\subsection{Fourier transform infrared spectroscopy with attenuated total reflection (FTIR-ATR)}

FTIR-ATR with horizontal mono-rebound attenuated total reflection accessory was performed with a Nicolet 6700 Spectrometer equipped with deuterated triglycine sulfate detector. An accessory with pressure control was used to equalize the pressure in the different solid samples. A prism of $\mathrm{ZnSe}$ was used and spectra were collected with a resolution of $4 \mathrm{~cm}^{-1}$ and 400 scans were averaged for each sample. Uncoated PES fabrics and fabrics coated with $1 \mathrm{G}, 2 \mathrm{G}, 3 \mathrm{G}, 4 \mathrm{G}, 1 \mathrm{G}+\mathrm{TiO}_{2}, 2 \mathrm{G}+\mathrm{TiO}_{2}, 3 \mathrm{G}+\mathrm{TiO}_{2}$ and $4 \mathrm{G}+\mathrm{TiO}_{2}$ were analyzed.

\subsection{X-ray photoelectron spectroscopy (XPS)}

XPS analyses were conducted at a base pressure of $5 \times 10^{-10}$ mbars and a temperature around $-100^{\circ} \mathrm{C}$. XPS spectra were obtained with a VG-Microtech Multilab electron spectrometer by using unmonochromatized $\mathrm{Mg} \mathrm{K} \alpha(1253.6 \mathrm{eV})$ radiation from a twin anode source operating at $300 \mathrm{~W}(20 \mathrm{~mA}, 15 \mathrm{kV})$. The binding energy (BE) scale was calibrated with reference to the $\mathrm{C} 1 \mathrm{~s}$ line at $284.6 \mathrm{eV}$. C1s and 01s core levels XPS spectra were analyzed for the fabric coated with GO (PES-GO) and the fabric coated with RGO (PES-RGO). The purpose of these measurements was to measure the efficiency of the chemical reduction. The $01 \mathrm{~s} / \mathrm{C} 1 \mathrm{~s}$ ratio was employed as an indicator of the reduction achieved. $\mathrm{C} 1 \mathrm{~s}, \mathrm{O} 1 \mathrm{~s}$ and Ti2p core levels XPS spectra were analyzed for the $\mathrm{PES}-1 \mathrm{G}+\mathrm{TiO}_{2}$, $\mathrm{PES}-2 \mathrm{G}+\mathrm{TiO}_{2}, \quad \mathrm{PES}-3 \mathrm{G}+\mathrm{TiO}_{2}$ and $\mathrm{PES}-4 \mathrm{G}+\mathrm{TiO}_{2}$ fabrics.

\subsection{UV-vis diffuse reflectance spectra (DRS)}

UV-vis diffuse reflectance spectra (DRS) were obtained using a spectrophotometer ScanSpecUV-Vis, ScanSci equipped with an integrating sphere assembly, using Barium Sulfate $\left(\mathrm{BaSO}_{4}\right)$ as the reference sample. The spectra were recorded at room temperature in air within the range of $300-700 \mathrm{~nm}$. Spectra were obtained for the PES uncoated fabrics and coated with $1 \mathrm{G}, 2 \mathrm{G}, 3 \mathrm{G}, 4 \mathrm{G}, 1 \mathrm{G}+\mathrm{TiO}_{2}$, $2 \mathrm{G}+\mathrm{TiO}_{2}, 3 \mathrm{G}+\mathrm{TiO}_{2}$ and $4 \mathrm{G}+\mathrm{TiO}_{2}$.

\subsection{Electrochemical impedance spectroscopy (EIS) measurements}

An Autolab PGSTAT302 potentiostat/galvanostat was used to perform EIS measurements in the $10^{5}-10^{-2} \mathrm{~Hz}$ frequency range. The amplitude of the sinusoidal voltage used was $\pm 10 \mathrm{mV}$. Measurements were carried out in a two-electrode arrangement with two types of configuration: (a) the sample was located between two round copper electrodes $\left(A=1.33 \mathrm{~cm}^{2}\right)$ to measure the bulk resistance. (b) Two rectangular copper electrodes $(0.5 \mathrm{~cm} \times 1.5 \mathrm{~cm})$ separated by $1.5 \mathrm{~cm}$ pressing on the fabric sample. The measured area of the fabric with this configuration was a square of $1.5 \mathrm{~cm}$, so the measured impedance modulus $(\Omega)$ was equal to the surface resistivity $(\Omega / \square)$.

\subsection{Electrochemical impedance spectroscopy (EIS) measurements in solution}

A standard three-electrode design was employed to measure the EIS response of PES-RGO samples in $0.1 \mathrm{M} \mathrm{H}_{2} \mathrm{SO}_{4}$ solutions. An asymmetrical configuration metal/sample/electrolyte was employed. Samples were mounted on a stainless steel plate (employed to produce the electrical connection). $\mathrm{An} \mathrm{Ag} / \mathrm{AgCl}$ (3.5 M $\mathrm{KCl})$ electrode and stainless steel rod were employed as reference electrode and counter electrode, respectively. The effective area of the samples exposed to solution was $0.28 \mathrm{~cm}^{2}$.

The experimental results were also fitted using a non-linear least squares fitting minimization method by ZView software (version 2.7).

\subsection{Scanning electrochemical microscopy (SECM)}

SECM measurements were carried out with a scanning electrochemical microscope of Sensolytics. A three-electrode configuration cell consisting of a $100-\mu \mathrm{m}$-diameter Pt microelectrode, a Pt wire auxiliary electrode and $\mathrm{Ag} / \mathrm{AgCl}(3.5 \mathrm{M} \mathrm{KCl})$ reference electrode. The fabrics were not polarized and the experiments were performed at their open circuit potential. Measurements were performed in $\mathrm{K}_{4} \mathrm{Fe}(\mathrm{CN})_{6} 0.01 \mathrm{M}$ and $0.1 \mathrm{M} \mathrm{KCl}$ (supporting electrolyte). The potential of the microelectrode was fixed at $+0.4 \mathrm{~V}$, potential at which the reduced form of the redox mediator is oxidized at its diffusion limit. All the experiments were carried out in inert nitrogen atmosphere. The substrates were samples $(0.5 \mathrm{~cm} \times 0.5 \mathrm{~cm}) \mathrm{cut}$ from the fabrics and glued on glass microscope slides with epoxy resin. Approach curves were employed to test the electroactivity of the samples and the approach rate employed was $10 \mu \mathrm{m} \mathrm{s}^{-1}$.

In the experiments with irradiation, ultraviolet light was applied with a Thermo Oriel 66901 Universal Lamp Housing (mercury lamp $50 / 500 \mathrm{~W}$ ) operating at $300 \mathrm{~W}$. Light was conducted to the SECM with optical fiber. Measurements with UV light were performed with the microelectrode at a constant height of $50 \mu \mathrm{m}$ above the sample. The variation of the oxidation current at $+0.4 \mathrm{~V}$ with time and pulses of irradiation applied was registered.

\subsection{Photocatalytic measurements}

The photocatalytic activity of all samples was evaluated by measuring the degradation rates of Rhodamine $B(\mathrm{Rh}-\mathrm{B})$ aqueous solutions ( $4 \mathrm{mg} / \mathrm{L}$ ) under ultraviolet (UV) light irradiation. Rh-B (an important xanthene cationic dye) was selected because of its welldefined optical absorption characteristics and good resistance to light degradation (the so-called dye sensitization). Moreover, this organic dye is one of the most common pollutants present in the effluents from textile industries in developed countries.

In a typical experiment, the PES-RGO/TiO 2 samples $(10 \mathrm{~cm} \times 10 \mathrm{~cm})$ were dipped into a flask filled with $400 \mathrm{~mL}$ of Rh-B aqueous solution. The system was stirred for $30 \mathrm{~min}$ in the dark to reach the adsorption-desorption equilibrium and then placed in an UV simulation chamber. Next, the samples were irradiated with a $300 \mathrm{~W}$ UV lamp (ULTRA-VITALUX $300 \mathrm{~W}$ E27) placed at a distance around $20 \mathrm{~cm}$ above the sample's surface. The average irradiance was around $40 \mathrm{~W} / \mathrm{m}^{2}$ (measured with a UV light Meter LTLutron YK-35UV).

The absorbance of the Rh-B solution was monitored during $420 \mathrm{~min}$ (at time intervals of $40 \mathrm{~min}$ up to $120 \mathrm{~min}$ ) and then at intervals of $60 \mathrm{~min}$ up to 420 using a spectrophotometer (ScanSpecUV-Vis, ScanSci) in the range of $300-700 \mathrm{~nm}$. For this, some aliquots of Rh-B solution $(3.5 \mathrm{~mL})$ were taken out and then 

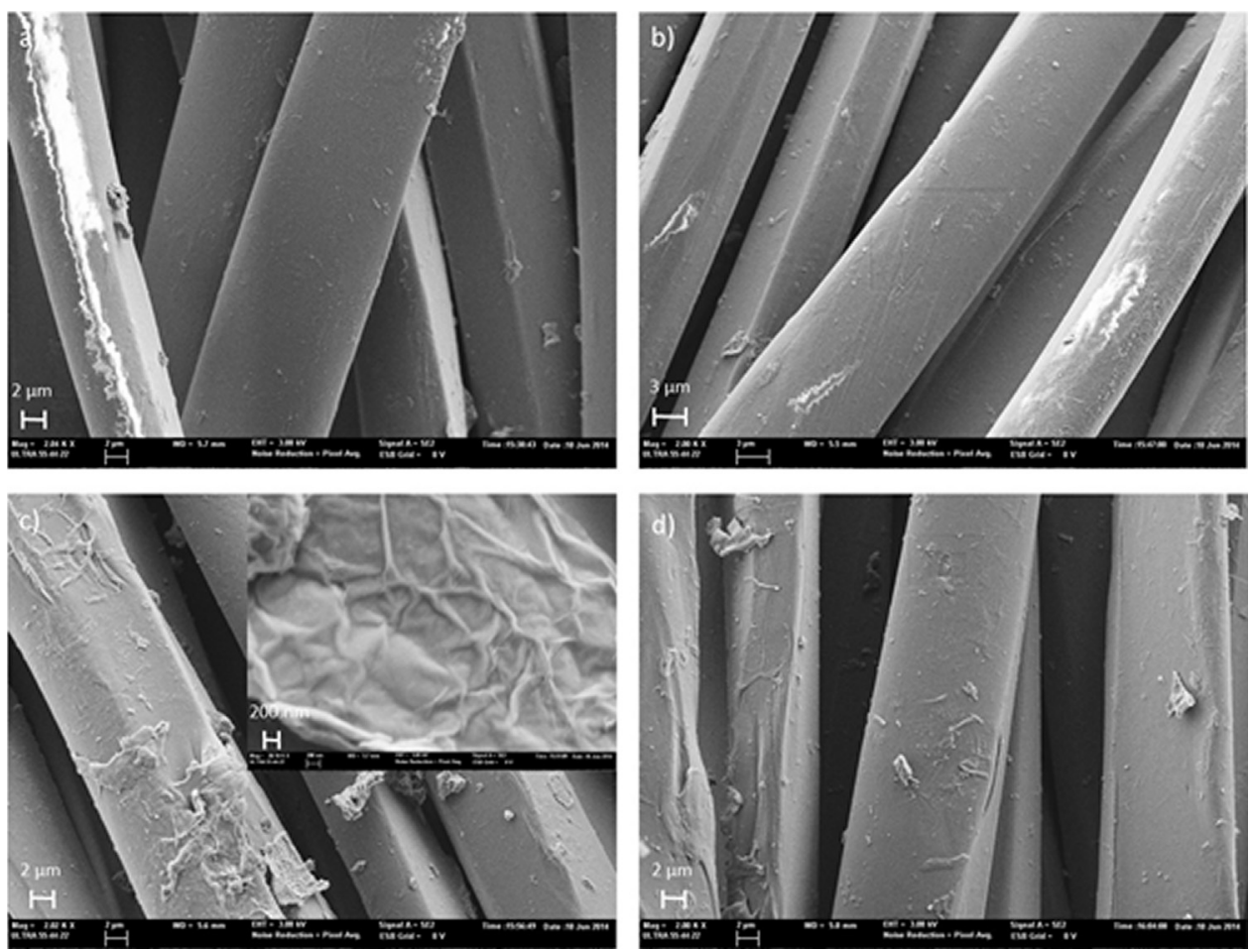

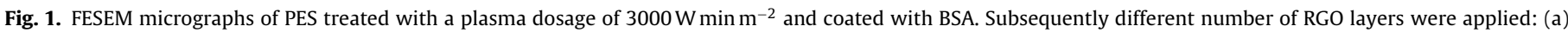
PES-1G ( $\times 2000)$, (b) PES-2G ( $\times 2000)$, (c) PES-3G $(\times 2000)$ (inset $\times 20000)$ and $(d)$ PES-4G $(\times 2000)$.

analyzed by monitoring the magnitude variation of its main absorption peak (around $564 \mathrm{~nm}$ ). The rate of Rh-B consumed in a chemical reaction can be written as:

$$
-\frac{d C}{d t}=K C^{n}
$$

where $C$ is the concentration of the Rh-B aqueous solution, $n$ is the kinetics order of the chemical reaction, and $k$ is the rate constant of the photodegradation process.

At low concentrations and for a specific time instant, the absorbance of the solution, $A_{t}$ is related to the solution's concentration through the Beer-Lambert law, that is, $A_{t}=\varepsilon \cdot l \cdot C_{t}$, where $\varepsilon$ is the molar extinction coefficient, $l$ is the light path length, and $C_{t}$ is the solution concentration. For a first-order kinetics reaction, the photodegradation efficiency, $\eta$, of Rh-B can be calculated according to the following equation:

$\eta(\%)=\left[1-\left(\frac{A_{t}}{A_{0}}\right)\right] \times 100$

where $A_{0}$ is the absorbance at zero time. Therefore, the change of Rh-B concentration can be evaluated by measuring the change in the intensity of its main absorption peak.

\section{Results and discussion}

\subsection{Atomic force microscopy (AFM)}

As can be observed in Fig. S1, the plasma treatment produced an increase of the PES fibers' roughness. The surface of the fibers of untreated fabrics is quite smooth with no remarkable features (Fig. S1a). The plasma treatment creates a rougher surface on the surface of the fibers as can be observed in Fig. S1b. This roughness is produced due to the removal of part of material from the surface of the fibers. In addition, functional groups were created on the surface of the fabric. These functional groups decreased the water contact angle (was drastically reduced from $130^{\circ} \pm 6^{\circ}$ to $5^{\circ} \pm 4^{\circ}$ ) and increased the surface energy from $10.5 \mathrm{~mJ} \mathrm{~m}^{-2}$ to $124.6 \mathrm{~mJ} \mathrm{~m}^{-2}$. However, the functional groups created on the surface of the fibers have negative charge, hence the self-assembly of the GO sheets was not possible since $\mathrm{GO}$ also possess negative charges on its surface. This is why an intermediate layer of bovine serum albumin (BSA) (which possesses positive charge) was employed [51]. The BSA layer allowed the fixation of the GO sheets on the surface of the fibers. Fig. S1c shows the topography of the fibers after being treated with plasma and coated with BSA and RGO. As can be seen, the roughness of the surface produced after the plasma treatment was substantially reduced due to the assembly of the RGO sheets. Instead of this, the characteristic wrinkled surface of RGO sheets could be observed on the AFM image. The interaction of plasmatreated fabric/BSA and the GO sheets is produced on one side of the RGO sheets, the other side remains free and it is afterwards chemically reduced to produce the restoration of the $\mathrm{sp}^{2}$ structure, which produces an increase of conductivity.

\subsection{Field emission scanning electron microscopy (FESEM)}

Fig. 1 shows the micrographs of the PES fabrics treated with plasma, coated with BSA and with different number of RGO layers (PES-1G, PES-2G, PES-3G and PES-4G). The micrograph of original PES is not shown since the fibers are plain with no remarkable features as observed by AFM (Fig. S1a). Fig. 1a shows the sample coated with only one RGO layer. Apparently no distinctive features were observed despite the fact that the sample was completely coated with RGO since its color changed from the white color of polyester to black color of RGO (Fig. S2). The samples coated with GO presented the characteristic brown color of GO; its reduction changed the color to the characteristic black color of RGO. As the number of RGO layers increased to 2, 3 and 4 (Fig. 1b-d), it could be seen the apparition of more RGO sheets and particles in the micrographs. The inset in Fig. 1c shows the magnification of a RGO sheet deposited on a PES fiber. As can be seen, its surface is characteristically wrinkled. 

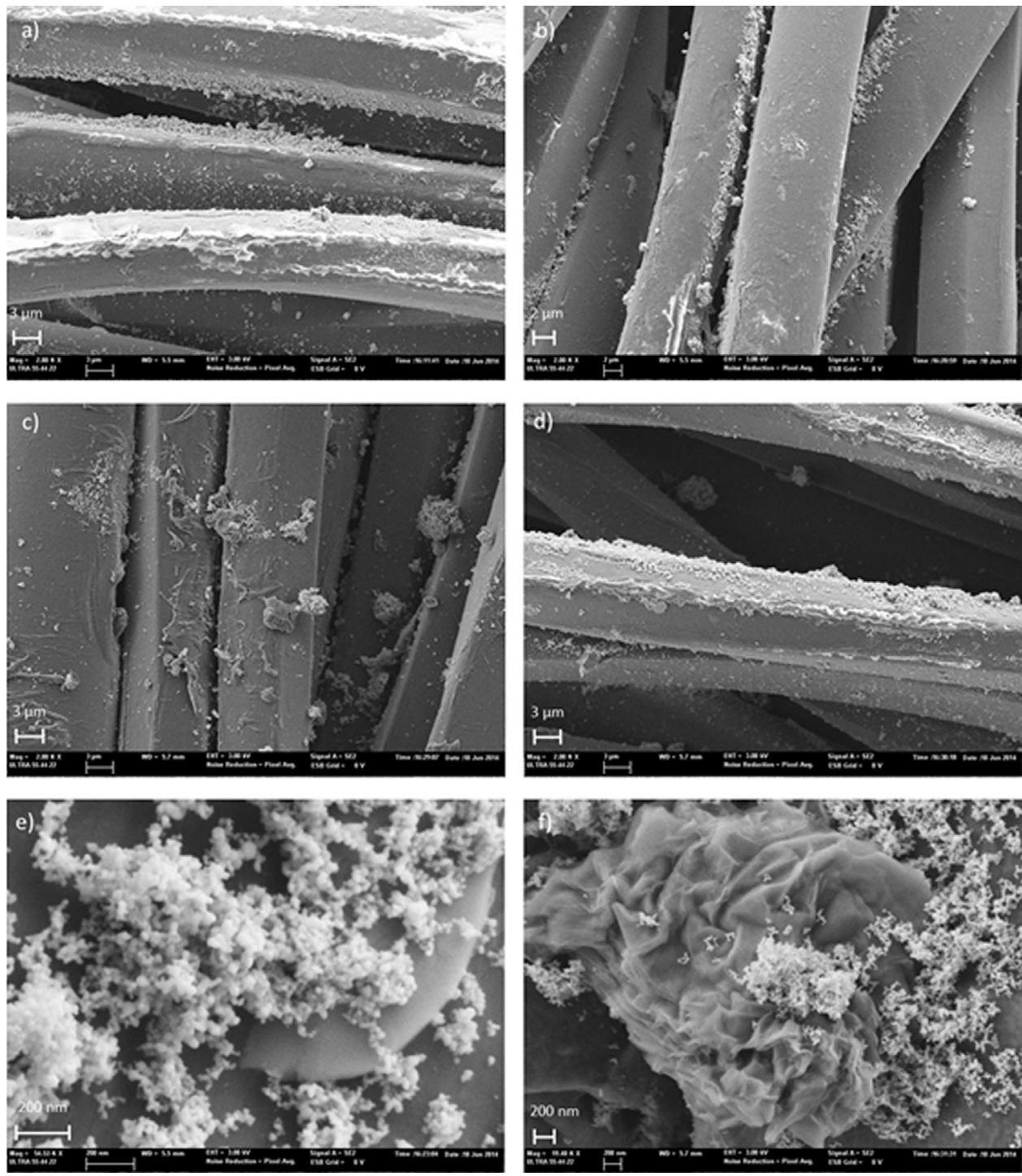

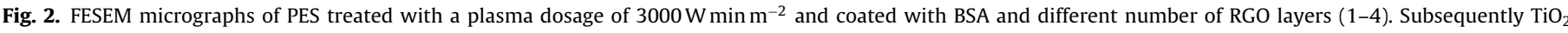

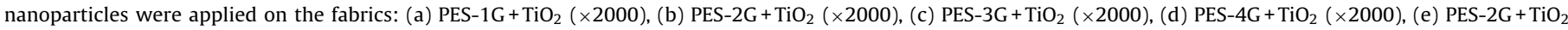
$(\times 20000)$, and (f) PES-3G $+\mathrm{TiO}_{2}(\times 55000)$.

The apparition of these wrinkles on GO has been attributed to the interaction between adjacent individual GO sheets [57].

Fig. 2a-d shows the fabrics of PES-1G, PES-2G, PES-3G and PES$4 \mathrm{G}$, respectively, all of them coated with $\mathrm{TiO}_{2}$ nanoparticles. In all the micrographs, the presence of $\mathrm{TiO}_{2}$ nanoparticles aggregates on the RGO coatings can be observed. Although GO is reduced, the total reduction of GO is not possible and RGO still presents negative charges due to the presence of oxidized functional groups over a wide range of $\mathrm{pH}[58,59]$. The zeta-potential $(\zeta)$ curve for the $\mathrm{TiO}_{2}$ nanoparticles employed in this work is shown in Fig. S3. Anatase and rutile have identical chemical composition but different crystal systems and thus, their isoelectric point (IEP) occurs at different $\mathrm{pH}$ values, 4.7 vs. 6.2 , respectively. The isoelectric $\mathrm{pH}$ value was found to be $\sim 5.2$ [60]. This is an acceptable value since it reflects the effect of the mixture of the two crystalline phases. From Fig. S3 it is possible to observe that for $\mathrm{pH}>5$ the $\mathrm{TiO}_{2}$ particles present negative $\zeta$-potential values that evidence the negative nature of its surface electrical charges, which also contributes for the $\mathrm{TiO}_{2}$ suspension stability via the appearance of repulsive electrostatic forces (Coulomb forces) [60]. $\mathrm{TiO}_{2}$ also presents negative charges since the $\mathrm{pH}$ of the $\mathrm{TiO}_{2}$ solutions $\left(5 \mathrm{~g} \mathrm{~L}^{-1}\right)$ employed was near to 6 .
In these conditions the assembly of the $\mathrm{TiO}_{2}$ nanoparticles on the RGO coatings is possible due to the diminution of the $\zeta$-potential after $\mathrm{GO}$ reduction. The reduction of the electrostatic repulsions allows the nanoparticles to move closer to the surface of the sample due to the Brownian motion. Nanoparticles are then captured and finally retained due to the functional groups on the surface (in this case the functional groups present on RGO's surface) [61]. Fig. 2e shows the magnified $\mathrm{TiO}_{2}$ nanoparticles on a PES-3G fabric. The size of the nanoparticles is in the range of $\mathrm{nm}$; the nominal size of the $\mathrm{TiO}_{2}$ nanoparticles was about $23 \mathrm{~nm}$. Fig. $2 \mathrm{f}$ shows the deposition of $\mathrm{TiO}_{2}$ nanoparticles on a RGO sheet. The characteristic wrinkles of RGO sheets help to locate the RGO sheets $[62,63]$.

Energy dispersive X-ray (EDX) characterization was employed to analyze the presence of $\mathrm{TiO}_{2}$ on the fabrics, a comparative composition study of the Ti atomic content was performed between the different samples. Fig. 3a shows the EDX characterization of the PES-RGO coated fabrics (PES-4G fabric is shown as example). As can be seen, only $C$ and $O$ appear in the EDX spectrum, both of them are present in the RGO structure, but also on the PES structure.

Fig. 3b shows the EDX spectrum of a PES-4G fabric coated with $\mathrm{TiO}_{2}$ nanoparticles. Since the $\mathrm{TiO}_{2}$ nanoparticles have been 
a)

Element Weight\% Atomic\%

$\begin{array}{lll}\text { CK } & 64.92 & 71.14 \\ \text { OK } & 35.08 & 28.86\end{array}$

Totals $\quad 200.00$

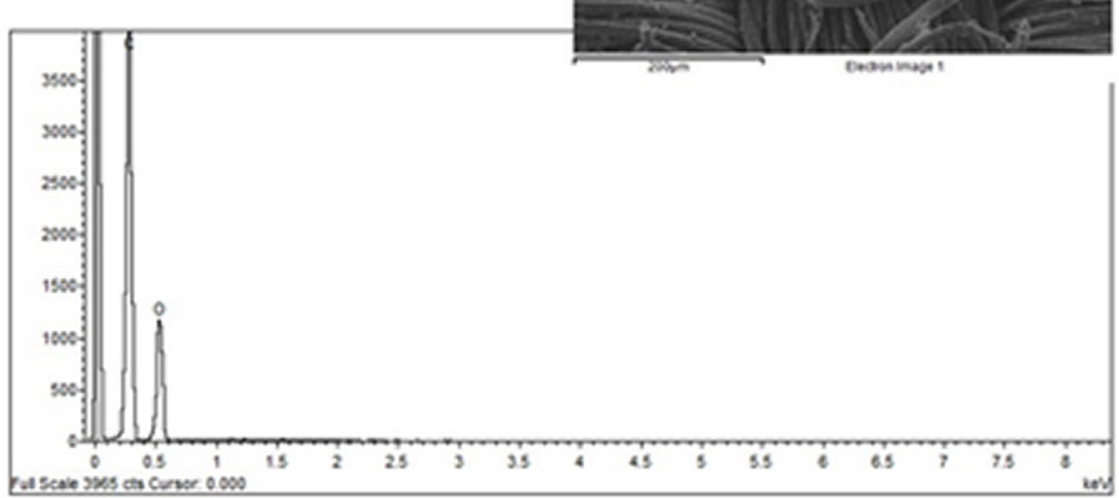

b)

$\begin{array}{lll}\text { Element } & \text { Weight\% Atomic } \\ \text { CK } & 61.76 & 69.54 \\ \text { OK } & 34.93 & 29.52 \\ \text { TiK } & 3.31 & 0.93\end{array}$
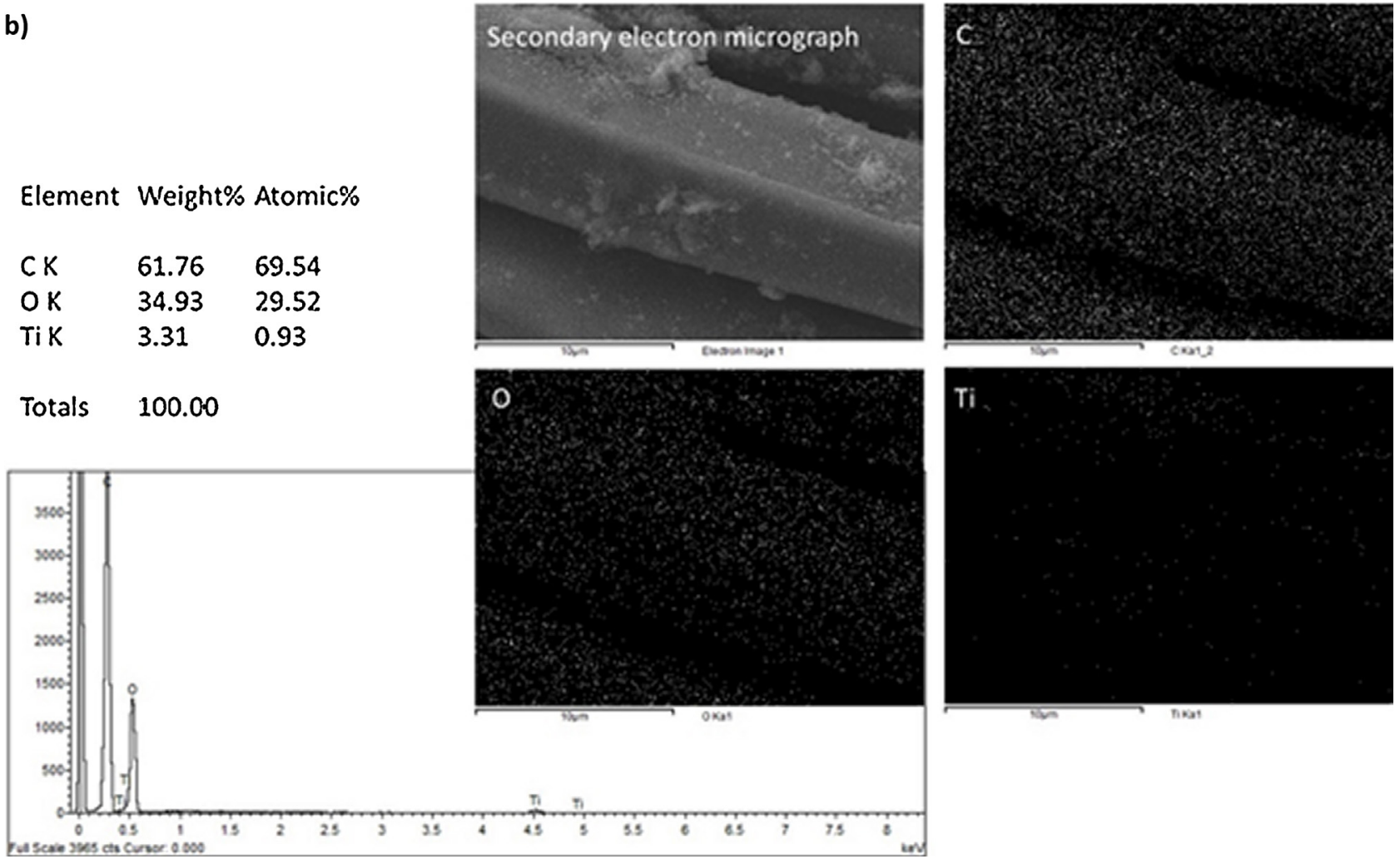

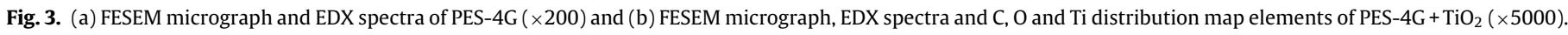

deposited onto the fabrics, different peaks attributed to Ti appear in the EDX spectrum. The major peak is located at $4.508 \mathrm{eV}$ and is attributed to the $K \alpha$ transition. The $L \alpha$ transition also appears at $0.452 \mathrm{eV}$. The distribution of $\mathrm{C}, \mathrm{O}$ and $\mathrm{Ti}$ can also be seen in the element distribution maps. $\mathrm{C}$ and $\mathrm{O}$ were well distributed on the fabrics due to the homogeneous RGO coating (as observed by the photographs shown in Fig. S2) but also for the PES substrate, since X-rays can penetrate several microns till the PES substrate. However, the deposition of $\mathrm{Ti}$ takes place in preferential zones. This preferential deposition in some regions could be due to the nature of padding process that was applied. A comparative analysis of the Ti atomic content was performed between the different samples. This is a relative value and not an absolute one, since the morphology of the sample and its roughness makes it complicated to calculate exactly the $\mathrm{TiO}_{2}$ content. To make it representative, EDX analyses were performed in 5 different zones of the fabric at $\times 100$ magnification in order to be comparable between them. The $\%$ atomic content of Ti was averaged for each sample and the values obtained were: $0.57 \pm 0.04,0.71 \pm 0.06,0.85 \pm 0.07$ and $0.47 \pm 0.03$ for PES-1G $+\mathrm{TiO}_{2}, \mathrm{PES}-2 \mathrm{G}+\mathrm{TiO}_{2}, \mathrm{PES}-3 \mathrm{G}+\mathrm{TiO}_{2}$ and $\mathrm{PES}-4 \mathrm{G}+\mathrm{TiO}_{2}$, 


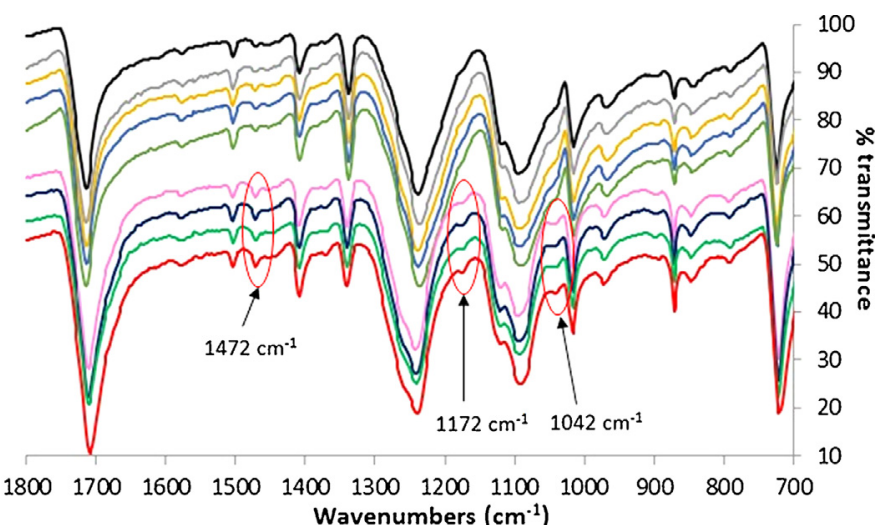

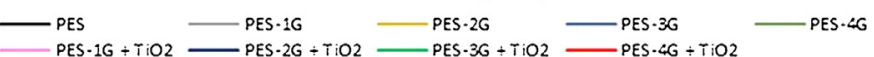

Fig. 4. FTIR-ATR spectra for PES, PES-1G, PES-2G, PES-3G, PES-4G, PES-1G + $\mathrm{TiO}_{2}$, $\mathrm{PES}-2 \mathrm{G}+\mathrm{TiO}_{2}, \mathrm{PES}-3 \mathrm{G}+\mathrm{TiO}_{2}$ and PES- $4 \mathrm{G}+\mathrm{TiO}_{2}$. Spectra collected with a resolution of $4 \mathrm{~cm}^{-1}$ and 400 scans.

respectively (Table S1). However, these values could be influenced by the zone of the fabric where the analysis was performed.

\section{3. $X$-ray diffraction $(X R D)$}

X-ray diffraction patterns were obtained for $\mathrm{TiO}_{2}$ powders (Fig. S4). Since $\mathrm{TiO}_{2}$ powders were a mixture of anatase and rutile, different peaks can be observed in the XRD pattern [60]. For this sample, the existence of both anatase and rutile phases can be identified by JCPDS file no. 21-1272 and no. 21-1276, respectively. The crystalline phases can be confirmed by the presence of $(101),(004)$ and (200) diffraction peaks, in the case of anatase phase; and (110), (111) and (002) diffraction peaks for the rutile crystalline phase. Using the Scherrer equation, it was observed that the mean crystallite grain size of the $\mathrm{TiO}_{2}$ particles was around $23 \mathrm{~nm}$ and $28 \mathrm{~nm}$ for anatase and rutile phases, respectively. These values were calculated from the full width at the half-maximum intensity of the (101) anatase diffraction peak (corresponding to $2 \theta=25.3^{\circ}$ ) and rutile diffraction peak (corresponding to $2 \theta=54.1^{\circ}$ ). Unmodified PES fabrics, PES-4G and PES-4G $+\mathrm{TiO}_{2}$ fabrics were also analyzed (Fig. S5). Two peaks appeared at around $23^{\circ}$ and $26^{\circ}$ due to polyester structure [64]. The modification with $\mathrm{RGO}$ and $\mathrm{RGO}+\mathrm{TiO}_{2}$ did not cause a significant modification of the XRD pattern due to the low quantity of RGO and $\mathrm{TiO}_{2}$ when compared to the PES fabric, which is the main component.

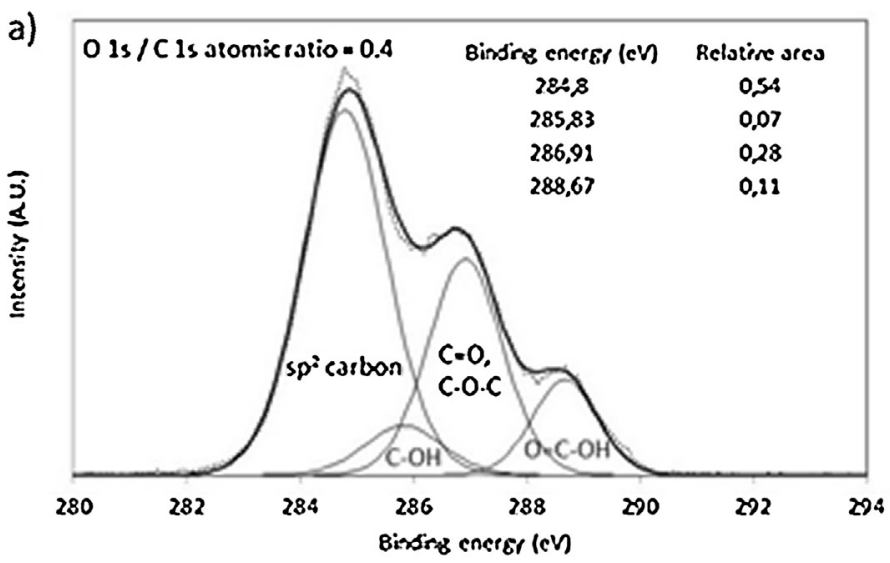

\subsection{Fourier transform infrared spectroscopy with attenuated total reflection (FTIR-ATR)}

Fig. 4 shows the FTIR spectra for the PES fabrics, the RGO coated PES fabrics, and the same fabrics coated also with $\mathrm{TiO}_{2}$. The spectrum of PES shows different bands that have been attributed in a previous work [65]. The deposit of RGO does not produce the appearance of any band since major bands of RGO coincide with that of PES [62]. When $\mathrm{TiO}_{2}$ was deposited on RGO-coated fabrics, the intensity of the band at $1472 \mathrm{~cm}^{-1}$ increased its intensity. This is easily observed if the intensity is compared with the neighboring band at around $1500 \mathrm{~cm}^{-1}$. This peak has been attributed to the presence of the symmetric stretching vibration of a bidentate carboxylic ligand with titanium atoms $[43,66]$. The intensity of this band was similar for all samples, which would indicate a similar amount of $\mathrm{TiO}_{2}$ deposited on the fabrics independently of the number of RGO coatings. The carboxylic groups arise from the incomplete reduction of GO. Its presence is observed in XPS section at binding energies around $288.8 \mathrm{eV}$ (Fig. S6). Two bands were also observed at $1042 \mathrm{~cm}^{-1}$ and $1172 \mathrm{~cm}^{-1}$ that were attributed to the stretching vibrations of $\mathrm{O}-\mathrm{O}$ bonds coordinated [67]. These peaks were not observed in the case of the fabrics without $\mathrm{TiO}_{2}$ and confirm the formation of bidentate carboxylic ligand.

\subsection{X-ray photoelectron spectroscopy (XPS)}

XPS was employed to measure the oxidation states as well as the composition of the different elements that compound the coatings (C, O and Ti). Prior, XPS measurements were performed in two samples to study the chemical reduction of GO to RGO: A sample of polyester coated with graphene oxide (PES-GO) and a sample of polyester coated with reduced graphene oxide (PES-RGO) (Fig. 5). It could be seen an important reduction of the oxygen content after chemical reduction, the $01 \mathrm{~s} / \mathrm{C} 1 \mathrm{~s}$ atomic ratio diminished from 0.4 to 0.2 . This reduction is due to the removal of oxidized groups. The removal of oxidized groups could also be observed in the C1s high resolution spectrum of both samples (Fig. 5). Both samples showed the typical peaks of $\mathrm{sp}^{2}$ carbon (284.4-284.8 eV), $\mathrm{C}-\mathrm{OH}(285.9 \mathrm{eV})$, $\mathrm{C}=\mathrm{O}, \mathrm{C}-\mathrm{O}-\mathrm{C}(287 \mathrm{eV})$ and $\mathrm{O}=\mathrm{C}-\mathrm{OH}(288.7-289 \mathrm{eV})$ groups [68]. A clear diminution of the peaks due to oxidized groups was observed. In addition, the $\mathrm{sp}^{2}$ content increased from 0.54 to 0.65 , indicating a partial restoration of the graphene structure. This produces the increase of conductivity observed after chemical reduction of GO to RGO.

Fig. $\mathrm{S} 6$ shows the high resolution $\mathrm{C} 1 \mathrm{~s}$ core level spectra for PES$1 \mathrm{G}+\mathrm{TiO}_{2}$ (Fig. S6a), PES-2G $+\mathrm{TiO}_{2}$ (Fig. S6b), $\mathrm{PES}-3 \mathrm{G}+\mathrm{TiO}_{2}$ (Fig. S6c)

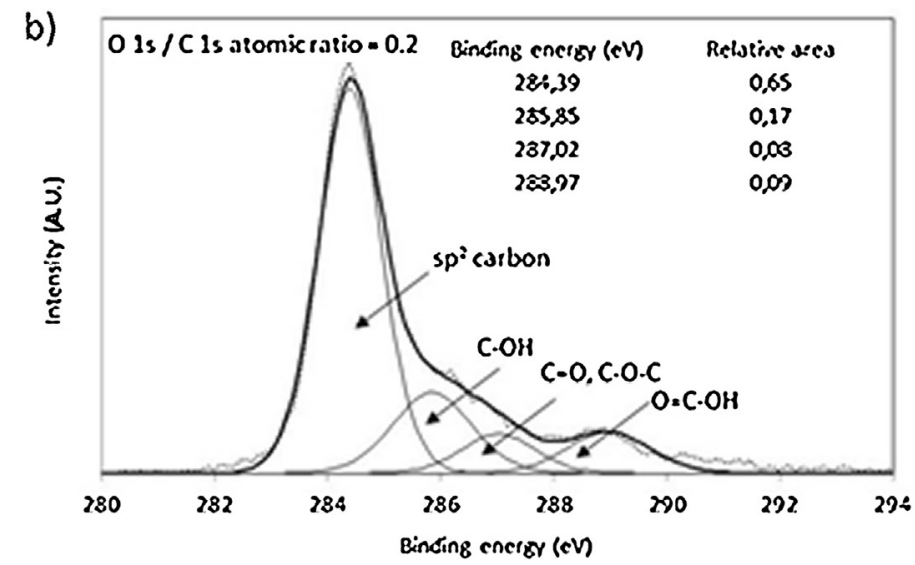

Fig. 5. High resolution C1s XPS core level spectrum for: (a) PES-GO and (b) PES-1G samples. 
Table 1

$\%$ atomic content for the different photocatalytic fabrics, obtained by XPS.

\begin{tabular}{|c|c|c|c|c|}
\hline \multirow[t]{2}{*}{ Element } & \multicolumn{4}{|c|}{$\%$ atomic content } \\
\hline & $\mathrm{PES}-1 \mathrm{G}+\mathrm{TiO}_{2}$ & $\mathrm{PES}-2 \mathrm{G}+\mathrm{TiO}_{2}$ & $\mathrm{PES}-3 \mathrm{G}+\mathrm{TiO}_{2}$ & $\mathrm{PES}-4 \mathrm{G}+\mathrm{TiO}_{2}$ \\
\hline $\mathrm{C}$ & 72.63 & 78.98 & 75.6 & 77.82 \\
\hline $\mathrm{Ti}$ & 1.19 & 0.52 & 1.36 & 0.61 \\
\hline $\mathrm{O}$ & 26.17 & 20.51 & 23.04 & 21.57 \\
\hline $\mathrm{O} / \mathrm{C}$ ratio (corrected) & 0.33 & 0.25 & 0.27 & 0.26 \\
\hline
\end{tabular}

and PES-4G $+\mathrm{TiO}_{2}$ (Fig. S6d). Similar bands to these reported previously were observed in the spectra:

- The band at $284.6 \mathrm{eV}$ attributed to $\mathrm{sp}^{2}$ carbon [68].

- A band at $286.2-286.4 \mathrm{eV}$ which is attributed to $\mathrm{C}-\mathrm{OH}, \mathrm{C}=\mathrm{O}$ and $\mathrm{C}-\mathrm{O}-\mathrm{C}$ [68], in this case it could not be deconvoluted into two peaks as in Fig. 5.

- A band at 288.7-287.8 eV attributed to $\mathrm{O}=\mathrm{C}-\mathrm{OH}$ groups [68]. These groups were responsible for the fixation of $\mathrm{TiO}_{2}$ nanoparticles as explained in the FTIR-ATR section.

Fig. S7 shows the Ti2p high resolution spectra core level spectra for the different fabrics coated with $\mathrm{TiO}_{2}$. The $\mathrm{Ti} 2 \mathrm{p}^{1 / 2}$ and $\mathrm{Ti} 2 \mathrm{p}^{3 / 2}$ spin-orbital splitting photoelectrons were observed at $459-459.6 \mathrm{eV}$ and $465 \mathrm{eV}$, respectively. The separation of around $6 \mathrm{eV}$ is in agreement with bibliography [69]. The peaks were attributed to $\mathrm{Ti}^{4+}$, which is the oxidation state that presents $\mathrm{TiO}_{2}$.

Table 1 shows the elemental composition of the different fabrics coated with $\mathrm{TiO}_{2}$. It could be seen that the Ti content did not follow a clear trend. This could be due to the non-uniform distribution of $\mathrm{TiO}_{2}$ on the fabrics' surface and that XPS measurements focus on a small area (usually $1 \mathrm{~mm}^{2}$ ). The amount of oxidized functional groups available where $\mathrm{TiO}_{2}$ can be fixed is similar in all the fabrics as can be seen in Fig. S6. The $\mathrm{O} / \mathrm{C}$ ratio (which was corrected to remove the $\mathrm{O}$ arising from $\mathrm{TiO}_{2}$ ) was also very similar for all samples (0.25-0.27), except for the PES- $1 \mathrm{G}+\mathrm{TiO}_{2}$ sample (Table 1 ). Therefore no significant variations in the $\mathrm{TiO}_{2}$ content should be expected between the different fabrics. Variations measured by EDX and XPS could be influenced by the zone of analysis employed. FTIR-ATR measurements, which are measured over a larger area $\left(5 \mathrm{~cm}^{2}\right)$ showed a similar $\mathrm{TiO}_{2}$ content.

\subsection{UV-vis diffuse reflectance spectra (DRS)}

It is also important to characterize the light absorption of the fabrics, since this will give us an indication of its absorption properties. Fig. 6 shows the diffuse reflectance spectra for the different fabrics. Polyester showed the highest reflectance due to its white color (Fig. S8). In general, $\mathrm{TiO}_{2}$ coated samples showed a higher absorption in the UV region due to the presence of $\mathrm{TiO}_{2}$ which presents its absorption in this region. Moreover, the addition of more RGO layers induces the increase of absorbance in the UV region [37]. When PES fabrics were coated with one RGO coating (which is black-colored), reflectance decreased due to the strong absorption of RGO in the visible region. As the number of RGO coatings applied increased, the reflectance decreased due to a higher absorption of the RGO coatings. In the photographs presented in Fig. S2 it could be seen that the fabrics become more blackish as the number of RGO coatings increased. It has been reported that the enhanced absorption of RGO in the visible region can also promote the transfer of excited electrons from RGO to the conduction band of $\mathrm{TiO}_{2}$ and then are transferred to the surface of $\mathrm{TiO}_{2}$ where they react with oxygen to yield superoxide radicals that are able to oxidize organic compounds [50]. The stronger absorption intensity of light as the number of RGO coatings increase, suggests that higher photocatalytic activity could be obtained [37].

\subsection{Electrical characterization by electrochemical impedance spectroscopy (EIS)}

Fig. 7 shows the electrical characterization of the fabrics, performed by EIS. This technique allows the measurement of the impedance modulus $|Z|$ as well as the phase angle, which gives an indication about the conducting/insulating nature of the material. Two types of configuration were employed, the first one (in which the copper electrodes are located on the surface of the fabrics) was employed to measure the surface resistivity and the second one (in which the fabric is located between the copper electrodes) was employed to measure the bulk resistance.

Fig. 7a shows the representation of the impedance modulus $|Z|$ vs. the frequency with the configuration to measure the surface resistivity. The values obtained were $291 \mathrm{k} \Omega / \square, 179 \mathrm{k} \Omega / \square, 82 \mathrm{k} \Omega / \square$ and $71 \mathrm{k} \Omega / \square$ for PES-1G, PES-2G, PES-3G and PES-4G samples, respectively. The value of surface resistivity for PES is higher than $10^{11} \Omega / \square[62,63]$, therefore there is a decrease of 5 orders of magnitude in the surface resistivity after the RGO deposition. When GO is not reduced to RGO, the surface resistivity obtained was similar to that of PES [62,63]. GO is an insulating material due to the disrupted $\mathrm{sp}^{2}$ bonding networks [70]. The chemical reduction is able to partially restore the $\mathrm{sp}^{2}$ structure, and an electrical resistance decrease is observed due to this fact $[62,63]$. However, the elimination of oxidized groups is not complete and some functional groups remain on the RGO's surface [63].

Fig. 7b shows the representation of the impedance modulus $|Z|$ vs. frequency with the configuration to measure the bulk resistance. The values obtained were $2102 \Omega, 655 \Omega, 417 \Omega, 112 \Omega$ for PES-1G, PES-2G, PES-3G and PES-4G samples, respectively. The decrease of the impedance modulus when compared with polyester was higher than 8 orders of magnitude. In this case, there was also a gradual decrease of the impedance modulus with the increasing number of RGO layers. With more RGO layers, the interconnection between

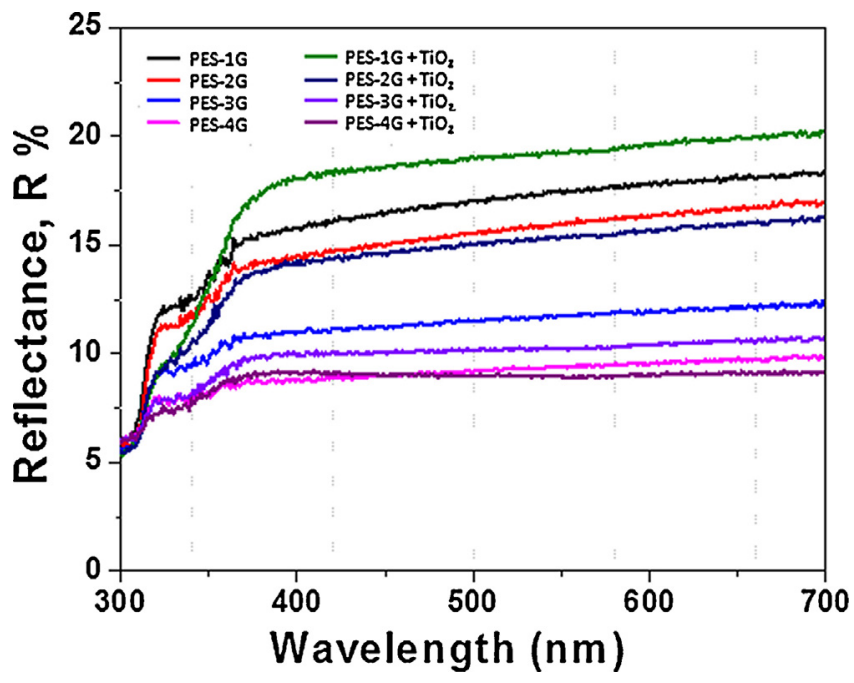

Fig. 6. UV-vis diffuse reflectance spectra (DRS) for PES-1G, PES-2G, PES-3G, PES-4G, PES-1G $+\mathrm{TiO}_{2}, \mathrm{PES}-2 \mathrm{G}+\mathrm{TiO}_{2}, \mathrm{PES}-3 \mathrm{G}+\mathrm{TiO}_{2}$ and $\mathrm{PES}-4 \mathrm{G}+\mathrm{TiO}_{2}$ fabrics. 
a)
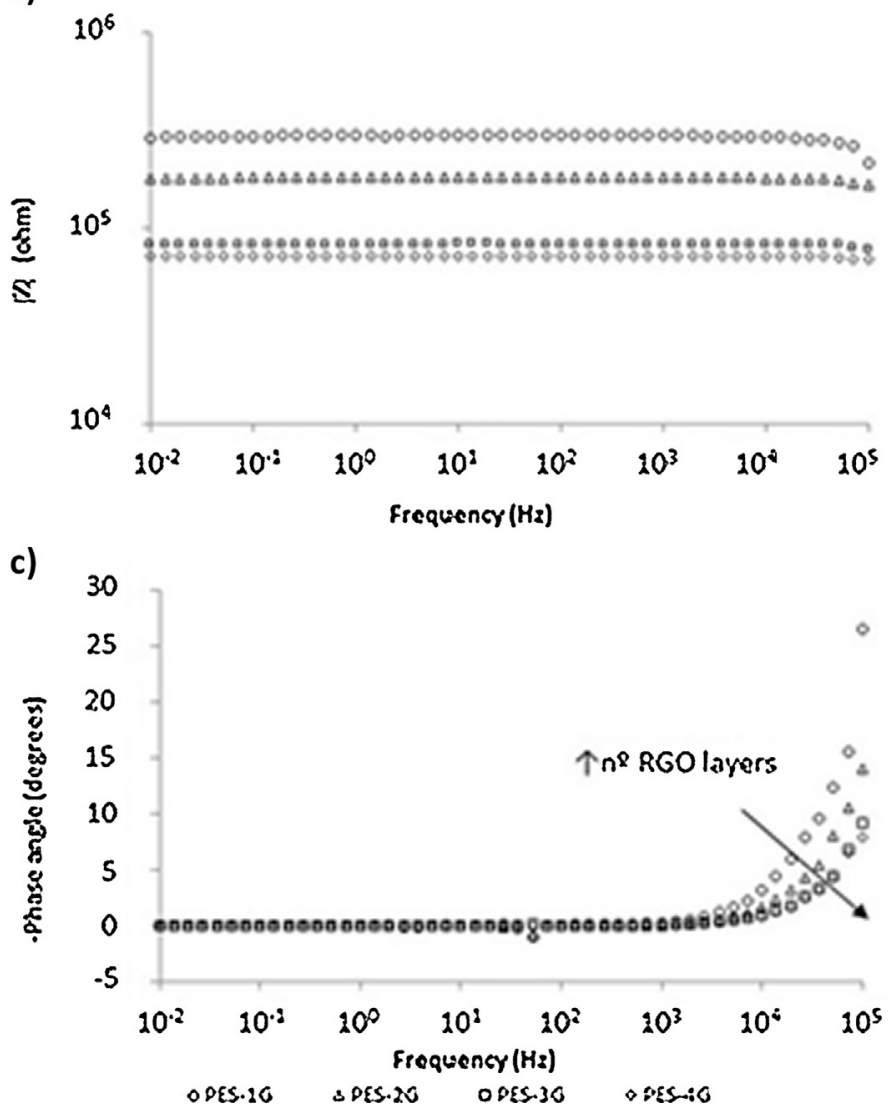

b)

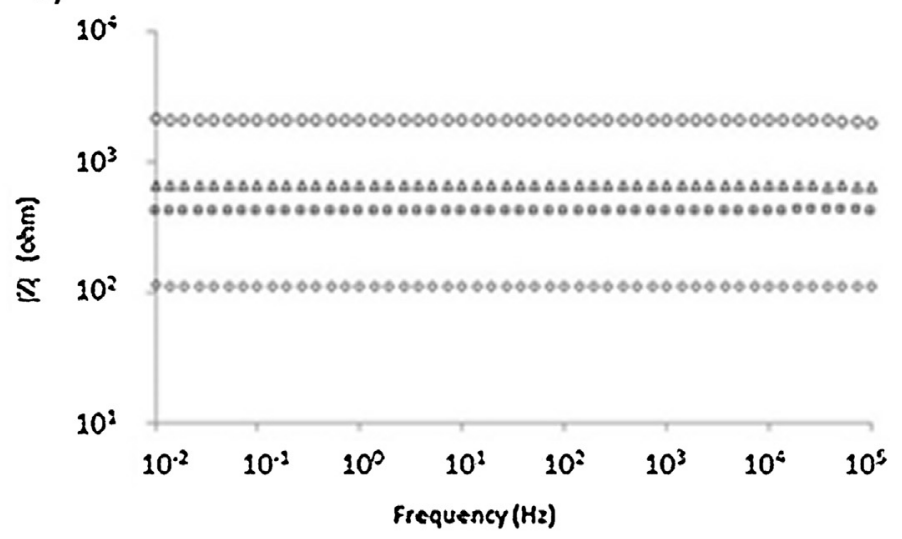

d)

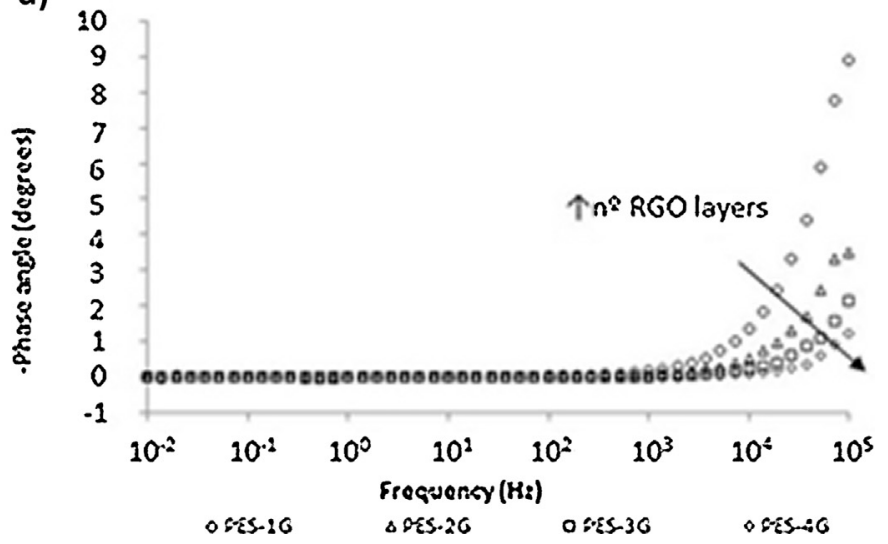

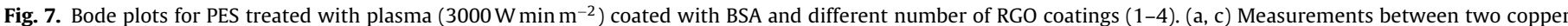

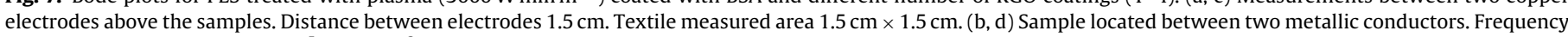
range for all the samples from $10^{5} \mathrm{~Hz}$ to $10^{-2} \mathrm{~Hz}$.

the individual RGO sheets was improved and the conduction pathways that allow the electrical flow were also improved. The number of RGO coatings was limited to 4 , because a higher number of RGO coatings only produce a slight improvement of conductivity [63].

Fig. 7c and d shows the -phase angle vs. the frequency for both types of configuration. In both cases, the RGO coated fabrics present values of - phase angle close to $0^{\circ}$, this value of -phase angle indicates a resistive behavior of the fabrics, typical of conductive materials. In this case, there is no phase delay between the stimulus applied and the response registered (the sinusoidal voltage applied is the stimulus and the sinusoidal intensity registered is the response registered). Only at high frequencies $\left(10^{3}-10^{5} \mathrm{~Hz}\right)$, values higher than $0^{\circ}$ were observed. At high frequencies the material still retained some capacitive behavior. As the number of RGO layers increased, the values of -phase angle at high frequencies $\left(10^{3}-10^{5} \mathrm{~Hz}\right)$ decreased. This also indicates a better conductivity with the increasing number of RGO coatings applied, due to the enhanced interconnection pathways created between the RGO sheets. PES presented values of - phase angle of $90^{\circ}$, which indicates a capacitive behavior typical of insulating materials [62,63]. In the case of pure PES, the sinusoidal voltage applied and the sinusoidal intensity registered were dephased due to the capacitive behavior of polyester.

\subsection{Electrochemical characterization by electrochemical impedance spectroscopy in solution (EIS)}

In the upper part of Fig. 8, the equivalent circuit employed to adjust the experimental data is shown. The different conductive fabrics were characterized by EIS in $0.1 \mathrm{M} \mathrm{H}_{2} \mathrm{SO}_{4}$ solution. The equivalent circuit is composed of the following components [71]:

$R_{\mathrm{S}}$ : corresponds to the electrolyte resistance between the working and reference electrodes.

$C P E$ : constant phase element that simulates the non-ideal behavior of the capacitor. It is composed of $C P E-T$ that gives the value of pseudo-capacitance at the electrolyte/RGO interface and CPE-P that gives an idea about the behavior of the CPE. When CPE-P is equal to 1 , the $C P E$ is equal to a capacitor $(C)$. If $C P E-P$ equals 0.5 , the $C P E$ represents the case of semi-infinite linear diffusion (and a straight line with $45^{\circ}$ slope is recorded on the Nyquist diagram). $R_{\mathrm{ct}}$ : corresponding to the charge transfer resistance at the $\mathrm{RGO} /$ electrolyte interface, in parallel with the CPE element. The combination in parallel of CPE and $R_{\mathrm{ct}}$ are responsible for the depression of the semicircle.

$W_{0}$ : corresponds to the finite-length Warburg diffusion. $W$ - $R$ : diffusion resistance. $W-T: l^{2} / D(\mathrm{~s}), l$ : length of the diffusion layer, $D$ : diffusion coefficient. $W$-P: Warburg exponent.

Fig. 8 shows the electrochemical characterization of the different conductive fabrics by EIS in $0.1 \mathrm{M} \mathrm{H}_{2} \mathrm{SO}_{4}$ solution. The adjustments of the data are presented as continuous lines and experimental data are shown as dotted lines. Mainly, two processes can be observed, the charge transfer process at high frequencies and the diffusion process at low frequencies. This analysis is mainly focused on the charge transfer process which indicates the electroactivity of the samples. Fig. 8a and $b$ shows the Nyquist plots for the different samples. The most important feature that can be observed in these figures 

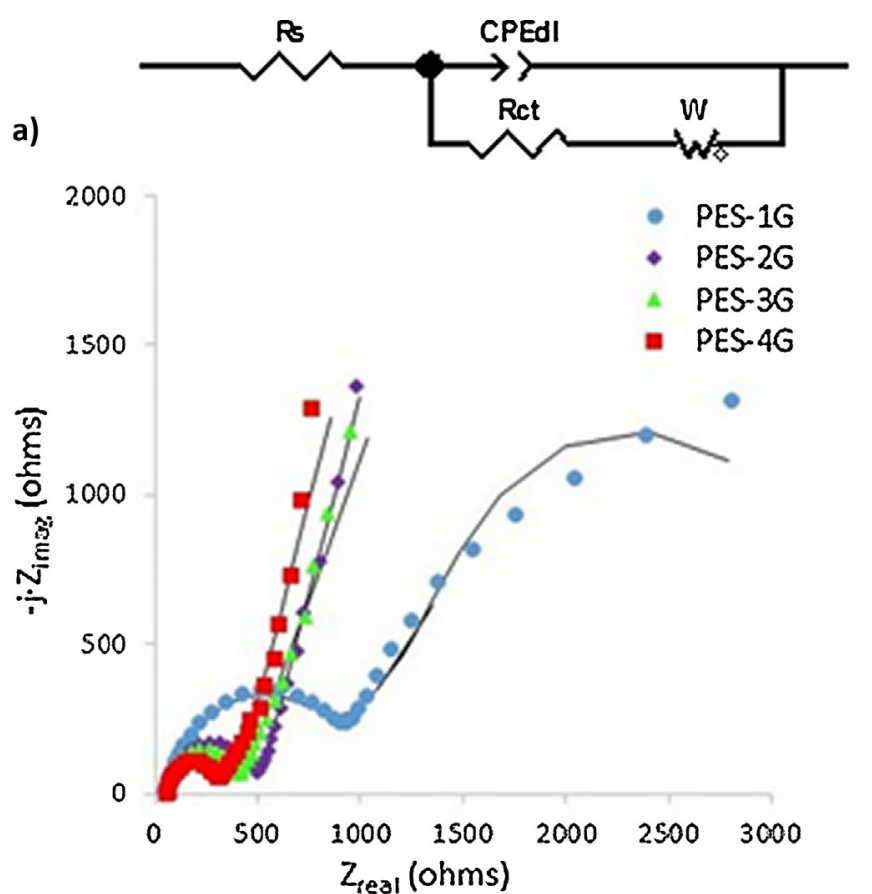

c)

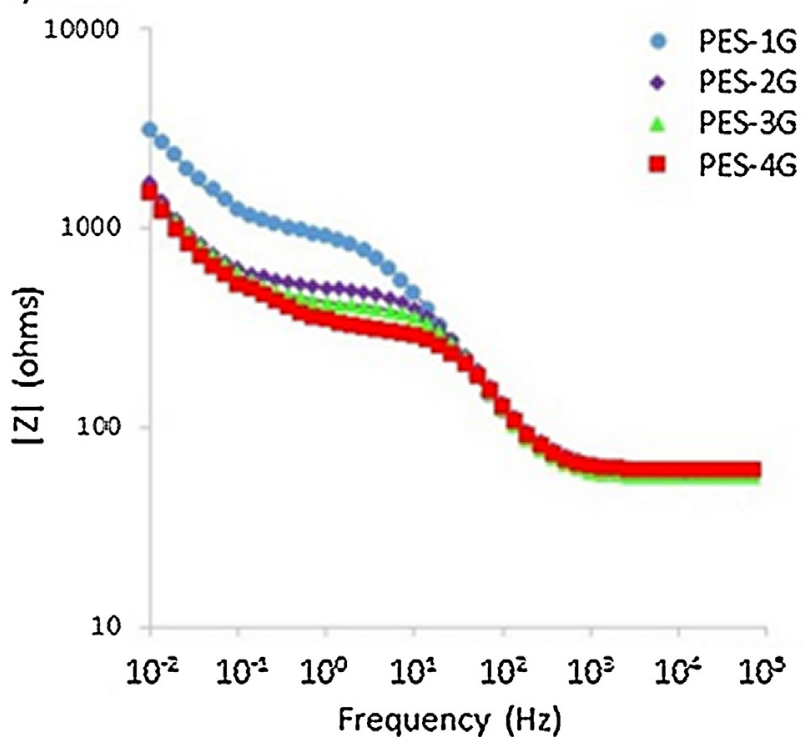

b)

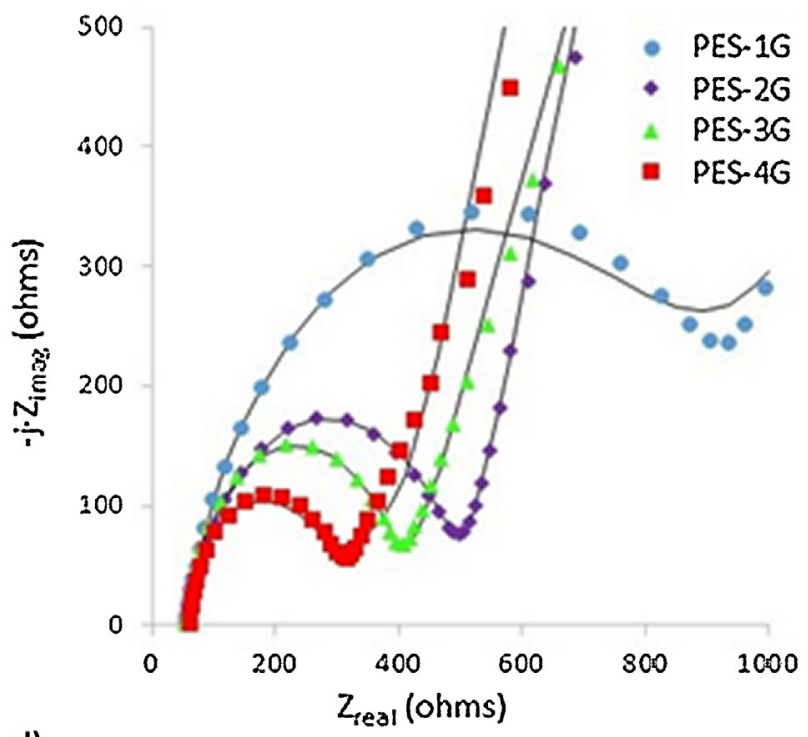

d)

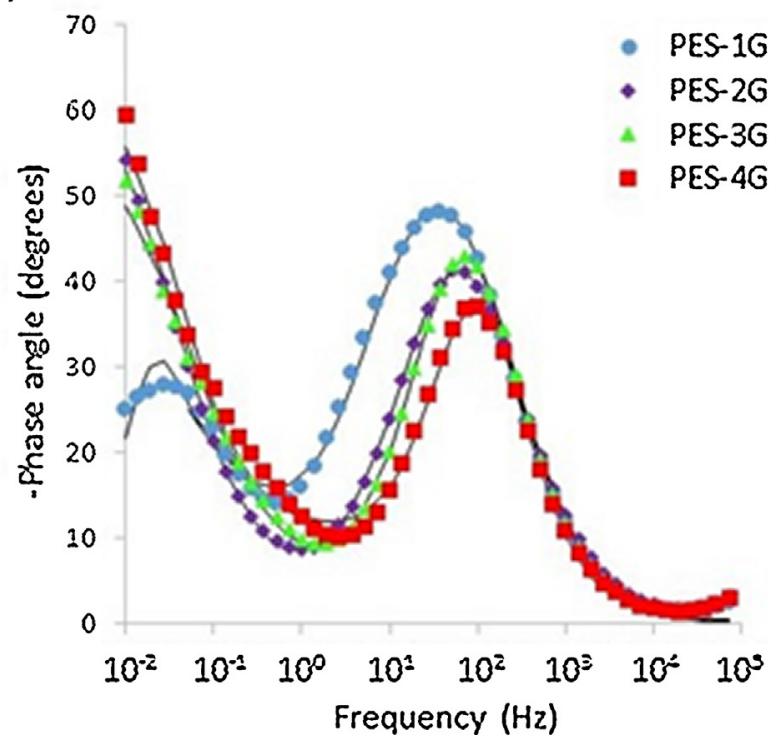

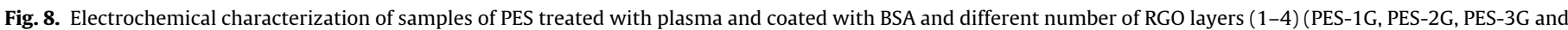

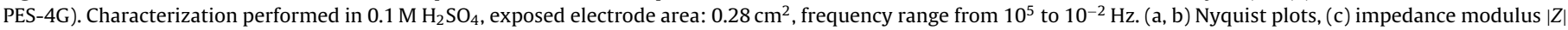
vs. frequency plot and (d) - phase angle vs. frequency plot. Equivalent circuit employed to adjust data is shown in the upper part of the image.

is the decrease of the charge transfer resistance $\left(R_{\mathrm{ct}}\right)$ at the RGO/electrolyte interface. This decrease of $R_{\mathrm{ct}}$ is represented by a smaller semicircle in the high frequency region (Fig. 8b). The adjusted values of $R_{\mathrm{ct}}$ can be observed in Table 2. Fig. 8c shows the representation of the impedance modulus $|Z|$ vs. the frequency. As can be seen, in general, there is a decrease of the impedance

Table 2

Results of the fitting of impedance data of PES-G samples in $0.1 \mathrm{M} \mathrm{H}_{2} \mathrm{SO}_{4}$. Data obtained by the equivalent circuit shown in Fig. 4 .

\begin{tabular}{llllll}
\hline Sample & Chi-squared & $R_{\mathrm{S}}$ & $C P E-T$ & $C P E-P$ & $R_{\mathrm{ct}}$ \\
\hline PES-1G & 0.0010 & 56.55 & $5.24 \times 10^{-5}$ & 0.83 & 727.3 \\
PES-2G & 0.0005 & 60.47 & $4.42 \times 10^{-5}$ & 0.84 & 444.5 \\
PES-3G & 0.0011 & 56.76 & $3.08 \times 10^{-5}$ & 0.90 & 347.7 \\
PES-4G & 0.0033 & 61.34 & $2.02 \times 10^{-5}$ & 0.96 & 197.3 \\
\hline
\end{tabular}

modulus as the number of RGO layers increase. Fig. $8 \mathrm{~d}$ shows the representation of the -phase angle vs. the frequency. There is a decrease of the - phase angle of the process associated with the charge transfer resistance $\left(R_{\mathrm{ct}}\right)$ as the number of RGO coatings increase. This decrease indicates a diminution of the pseudocapacitance as can also be seen in Table 2. This diminution of the pseudo-capacitance could be attributed to the achievement of a more compact RGO film on the fabrics as more RGO layers are deposited. The value of $C P E-P$ also increased with the number of RGO coatings (tending to 1 for the PES-4G sample). This increase shows that as the number of RGO coatings increase, the system tends to behave more like an ideal capacitor. There is also a displacement of the time constant of the charge transfer process $(\tau)$ to higher frequencies as the number of RGO coatings increase. The time constant is obtained from the frequency value at which the -phase angle is maximum $\left(\omega_{\max }\right)$. The time constant is defined as 
a)

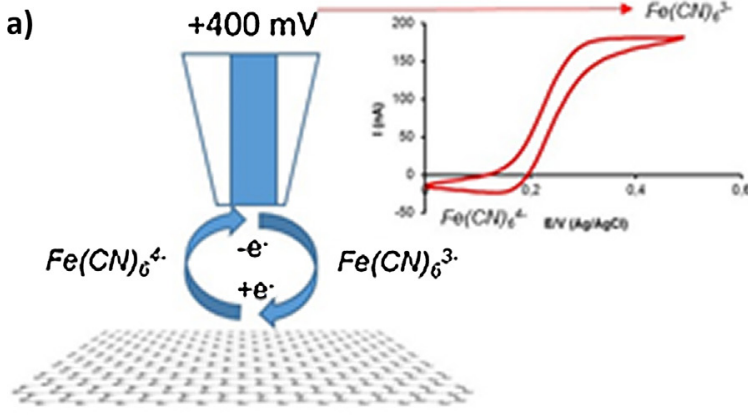

b)

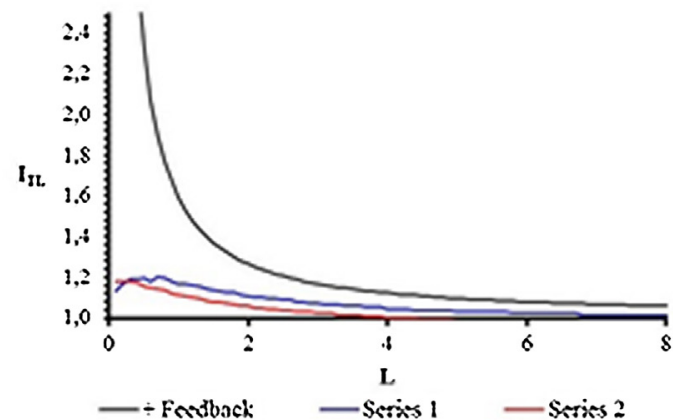

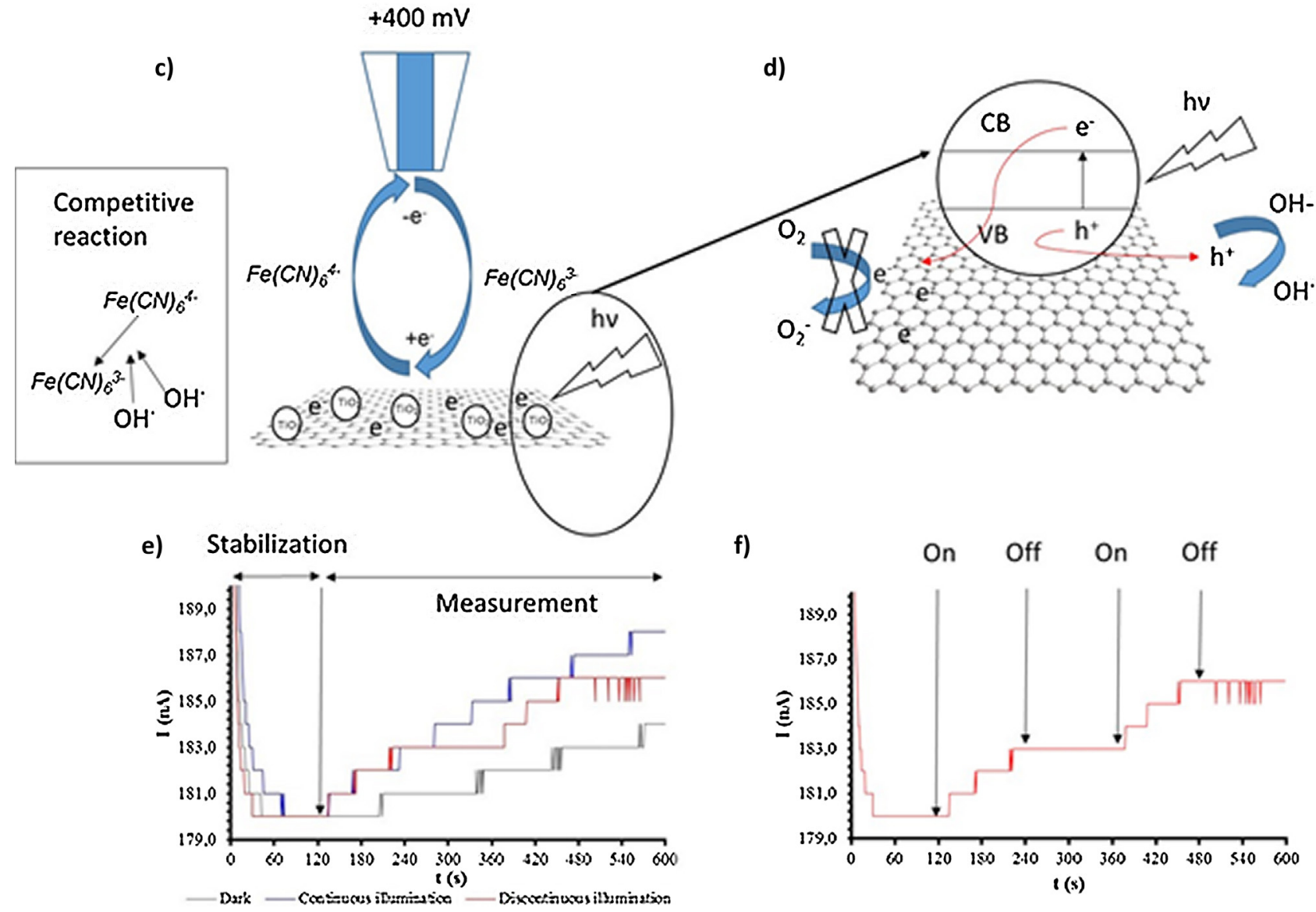

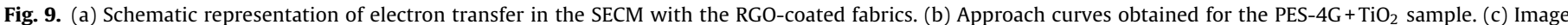

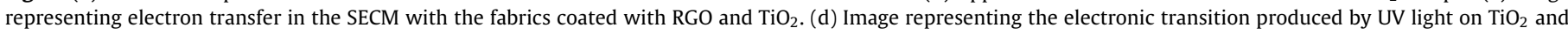

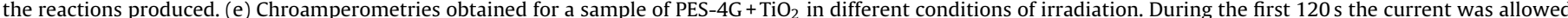

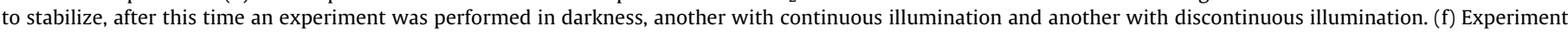

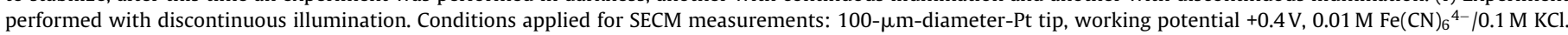

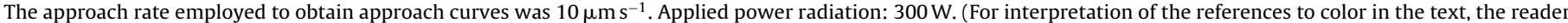
is referred to the web version of this article.)

the inverse of the $\omega_{\max }\left(\tau=1 / \omega_{\max }\right)$. The values of $\tau$ for the different samples were: $0.0268,0.0193,0.0139$ and $0.01 \mathrm{~s}$ for PES-1G, PES-2G, PES-3G and PES-4G fabrics, respectively. This change in the time constant indicates a more rapid charge transfer as the number of RGO coatings increase. The most electroactive sample was then the PES-4G one.

\subsection{Scanning electrochemical microscopy (SECM)}

The electroactivity of the fabrics coated with $\mathrm{RGO} / \mathrm{TiO}_{2}$ was tested by means of SECM technique in feedback mode. The oxidation current, when the reduced form of the redox mediator
(Red) is oxidized (Ox) on the surface of the microelectrode, is measured as the microelectrode approaches the surface of study (Fig. 9a). The potential of the microelectrode was fixed at $+0.4 \mathrm{~V}$, where the reduced form of the redox mediator $\left(\mathrm{Fe}(\mathrm{CN})_{6}{ }^{4-}\right)$ is oxidized to $\mathrm{Fe}(\mathrm{CN})_{6}{ }^{3-}$ on the microelectrode's surface at a diffusion controlled rate $\left(i_{\infty}\right)$ (Fig. 9a). The measured current is defined as $i_{\infty}=4 \cdot n \cdot F \cdot D \cdot C \cdot a$, where $n$ is the number of electrons, $F$ is the Faraday constant, $D$ is diffusion coefficient, $C$ is the bulk concentration of the redox mediator and $a$ is the radius of the microelectrode tip.

In approach curves, the normalized reduction current registered at the microelectrode $(I)$ is represented vs. the normalized distance $(L)$. The normalized current is defined as follows: $I=i / i_{\infty}$ where $i$ is 
the current measured at the microelectrode tip at a defined normalized distance and $i_{\infty}$ is the diffusion current defined above. The normalized currents depend on $R G\left(R G=R_{\mathrm{g}} / a\right)$, where $R_{\mathrm{g}}$ is the radius of the insulating glass surrounding the Pt tip of radius $a$ and the normalized distance $L$; where $L=d / a$ ( $d$ is the microelectrodesubstrate separation). The $R G$ of the microelectrode employed in this work was $R G \geq 20$.

Depending on the distance between the microelectrode and the substrate and the electroactivity of the substrate, different situations can happen:

- If the microelectrode is far away from the substrate, the diffusion current is measured $\left(i_{\infty}\right)$. Therefore, the normalized current $(I)$ is equal to 1 .

- If the microelectrode approaches a non-conductive substrate, there is a hindrance to the diffusion of Red species. The surface of the sample is not able to regenerate (reduce) the oxidized form of the redox mediator (Ox), hence there is a decrease of the oxidation current on the surface of the microelectrode, $i<i_{\infty}$. This situation is known as negative feedback [72] and is characterized by normalized current $(I)<1$.

- On the other hand, if the electrode is conductive, when the microelectrode approaches the surface of the sample, there is an increase of the reduced redox species flux (Red). The surface potential of the sample is able to regenerate (reduce) the redox mediator. This causes an increase of the oxidation current measured at the microelectrode, $i>i_{\infty}$. This case is known as positive feedback [72] and is characterized by normalized current $(I)>1$.

Experimental approach curves were compared with the theoretical one for positive feedback model, according to Eq. (4). According to Rajendran and Ananthi [73], Pade's approximation gives a close and simple equation with less relative error for all distances and valid for $R G>10$. The approximate formula of the steady-state normalized current assuming positive feedback for finite conductive substrate together with finite insulating glass thickness is:

$I_{T}^{C}=\left[\frac{1+1.5647 / L+1.316855 / L^{2}+0.4919707 / L^{3}}{1+1.1234 / L+0.626395 / L^{2}}\right]$

Fig. 9a shows the representation of the electron transfer between the microelectrode/redox mediator and the RGO-coated fabric/redox mediator. The oxidation of the redox mediator is produced on the surface of the microelectrode. Conversely, the reduction of the redox mediator is produced on the surface of the RGO-coated fabric. It has been demonstrated that RGO-coated fabrics can act either as a reductant or oxidant [63]. In this case, its reductant character has been selected to carry out the measurements in order to study the electron production on the $\mathrm{TiO}_{2}$ nanoparticles.

Fig. 9b shows the approach curves obtained for the PES$4 \mathrm{G}+\mathrm{TiO}_{2}$ sample. The sample of PES-4G was selected because it showed the lowest charge transfer resistance, as measured by EIS. As can be seen, positive feedback was obtained with values around 1.2 for a value of $L=0.5$. In this case, the positive feedback indicates that the surface of the fabric is able to reduce the oxidized form of the redox mediator. As the microelectrode approaches to the surface of the fabric, there is an increase in the flux of reduced species $\left(\mathrm{Fe}(\mathrm{CN})_{6}{ }^{4-}\right)$ that can be oxidized (to $\mathrm{Fe}(\mathrm{CN})_{6}{ }^{3-}$ ) on the surface of the microelectrode and an increase in the oxidation current is registered.

Fig. 9c and d shows the electronic transition produced by UV light irradiation on the $\mathrm{TiO}_{2}$ nanoparticles and the different reactions produced. The bandgap value for $\mathrm{TiO}_{2}$ is around $3.0-3.2 \mathrm{eV}$ which corresponds to a wavelength $<380 \mathrm{~nm}$ (UV region) [20]. The irradiation causes a transition of an electron $\left(\mathrm{e}^{-}\right)$from the valence band (VB) to the conduction band (CB). As a result, a hole $\left(\mathrm{h}^{+}\right)$ is also created in the valence band. The electrons are transferred to the surface of RGO by a percolation mechanism [20] where they accumulate and can react with the redox mediator, since electron transfer to $\mathrm{O}_{2}$ to produce $\mathrm{O}_{2}{ }^{-}$is not possible since the measurements were performed in deoxygenated/inert atmosphere [74]. This increase in the number of electrons on the surface of RGO would produce the reduction of more redox species that are later oxidized on the surface of the microelectrode. As a result, an increase in the oxidation current of the microelectrode would be registered. Nevertheless, there is a competitive reaction, holes react with hydroxyls and produce hydroxyl radicals $\left(\mathrm{OH}^{\bullet}\right)$ [20], hydroxyl radical is an oxidizer that competes with electrons in the oxidation/reduction of the redox mediator.

So, to measure the changes produced by irradiation, the measurement of the oxidation current on the surface of the microelectrode (at $+0.4 \mathrm{~V}$ ) was performed at constant height within the zone of positive feedback influence ( $d=25 \mu \mathrm{m}, L=0.5$ ). The oxidation current on the microelectrode was measured by chronoamperometry technique. First of all, the oxidation current was allowed to stabilize (the stabilization lasted 120 s). Once the oxidation current on the microelectrode was stabilized, the diffusion current was achieved $\left(i_{\infty}\right)$ and the different experiments were performed. The different experiments were performed in the same point and height $(25 \mu \mathrm{m})$. Three different conditions of illumination were applied (Fig. 9e):

- One experiment was performed without illumination (gray line). As can be seen, there is a tendency to increase the oxidation current with time due to a net accumulation of the reduced mediator form $\left(\mathrm{Fe}(\mathrm{CN})_{6}{ }^{4-}\right)$ with time. As can be seen, the oxidation current changed from 180 to $184 \mathrm{nA}$.

- In the second experiment (blue line), the current was allowed to stabilize and light was turned on for the following $8 \mathrm{~min}$. As can be seen, there was a constant increase of the current with time. In this case, the oxidation current changed from 180 to $188 \mathrm{nA}$. The difference was double than that obtained without illumination. The difference in the current can be assigned to the increase of the accumulated $\mathrm{Fe}(\mathrm{CN})_{6}{ }^{4-}$ produced by the reaction of $\mathrm{Fe}(\mathrm{CN})_{6}{ }^{3-}$ with the photogenerated electrons on $\mathrm{TiO}_{2}$ nanoparticles. The temperature change in the solution produced by the continuous irradiation was very low $\left(<0.5^{\circ} \mathrm{C}\right)$.

- In the third experiment (red line of Fig. 9e or f), after the stabilization period, a pulse of light was applied for 120 s. During the pulse application, there was an increase of $3 \mathrm{nA}$ in the oxidation current. After this time, the light was turned off for $120 \mathrm{~s}$ and the current did not vary during this time. Thereafter, light was turned on for $120 \mathrm{~s}$ and an increase of $3 \mathrm{nA}$ was obtained again. After this, light was turned off. The pulses of light are represented in Fig. $9 f$. In this case, the total change obtained in the oxidation current was $6 \mathrm{nA}$. Value lower than with continuous illumination ( $8 \mathrm{nA})$ since the exposure time was also lower.

Photoelectrons produced by irradiation on $\mathrm{RGO} / \mathrm{TiO}_{2}$ coated fabrics were clearly detected by SECM. In these conditions, reaction of the redox mediator with electrons prevail over $\mathrm{OH}^{\bullet}$ reaction with the redox mediator. Otherwise a decrease in the oxidation current would have been observed.

\subsection{Photocatalytic activity}

The photocatalytic activity of PES-G $+\mathrm{TiO}_{2}$ fabrics was evaluated in terms of degradation of Rh-B under UV light irradiation. Fig. S9 shows the control experiment where Rh-B solution is irradiated in the presence of PES fabric in the same conditions applied to the catalytic fabrics. During the first 40 min a slight adsorption was 


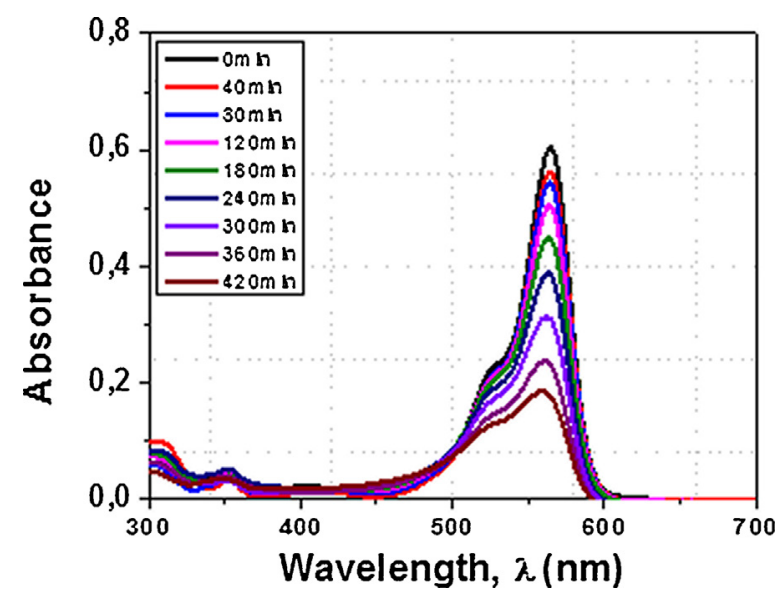

Fig. 10. Absorption spectra of Rh-B aqueous solution acquired at different irradiation times. The absorption data refer to the photocatalytic activity of PES-RGO $+\mathrm{TiO}_{2}$ inserted in a flask filled with $400 \mathrm{~mL}$ of $\mathrm{Rh}-\mathrm{B}(4 \mathrm{mg} / \mathrm{L})$ aqueous solution.

observed. Thereafter, absorbance increased with the increasing due to the evaporation of part of the water due to the heat generated by the UV lamp. The final absorbance of the solution was higher than the initial one, this discards degradation of Rh-B by UV irradiation. Adsorption was also minimal as explained.

Fig. 10 shows, for different irradiation times in the presence of a PES- $1 \mathrm{G}+\mathrm{TiO}_{2}$ fabric, the evolution of the absorption spectra of Rh-B solutions (initial concentration of $4 \mathrm{mg} / \mathrm{L}$ ).

As can be observed, the maximum absorption peak, at around $564 \mathrm{~nm}$, gradually decreased during UV irradiation. For this sample, the initial absorbance decreased about $70 \%$ after $420 \mathrm{~min}$. In fact, the color of the dye changed from dark red to light red. It is important to refer that under similar UV irradiation conditions, the absence of the photocatalyst did not affect the Rh-B absorption curves. This result indicates that the chemical oxidation-reduction mechanisms are occurring at the surface of the photocatalyst.

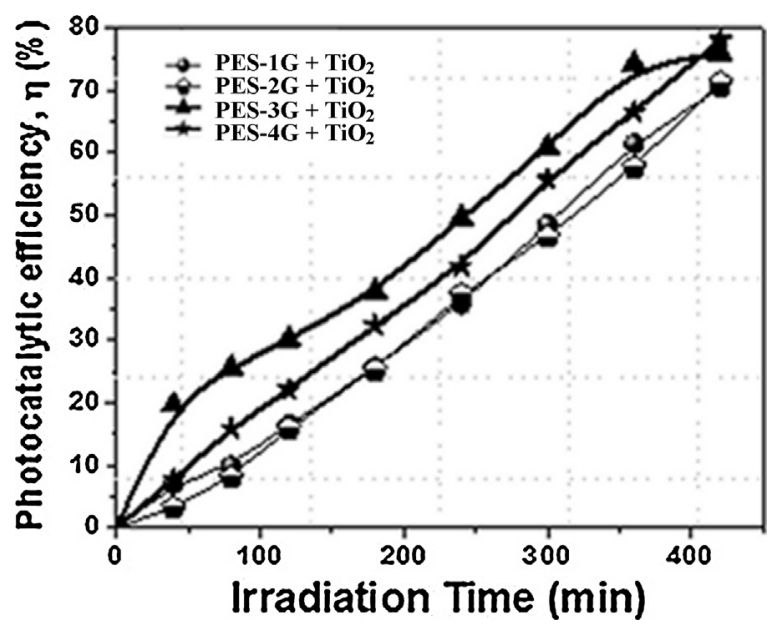

Fig. 11. Photocatalytic degradation, over time, of Rh-B aqueous solution in the presence of PES-RGO $+\mathrm{TiO}_{2}$ samples.

Using the absorption spectra of all the analyzed samples, it was possible to calculate the corresponding photocatalytic efficiencies $(\eta)$ by applying Eq. (3). Fig. 11 shows the variation with time of the photocatalytic degradation efficiency $(\eta)$ of Rh-B aqueous solution in the presence of PES-G $+\mathrm{TiO}_{2}$ samples.

By using the UV-vis spectroscopy data from all the PES$\mathrm{G}+\mathrm{TiO}_{2}$ samples, it was possible to determine for each fabric the photodegradation rate constant, $K$ for the Rh-B dye. Assuming pseudo-first-order reaction kinetics the calculated $K$ values are presented in Table 3.

The results presented in Table 3 show that there is a gradual increase of photocatalytic efficiency with the number of RGO layers. The sample with 4 RGO layers presented the highest $\eta$. The gradual increase in the $\eta$ could be attributed to a higher light absorption as DRS spectra have shown. In addition, the reduced charge transfer resistance and lower time constants promote the electron/hole
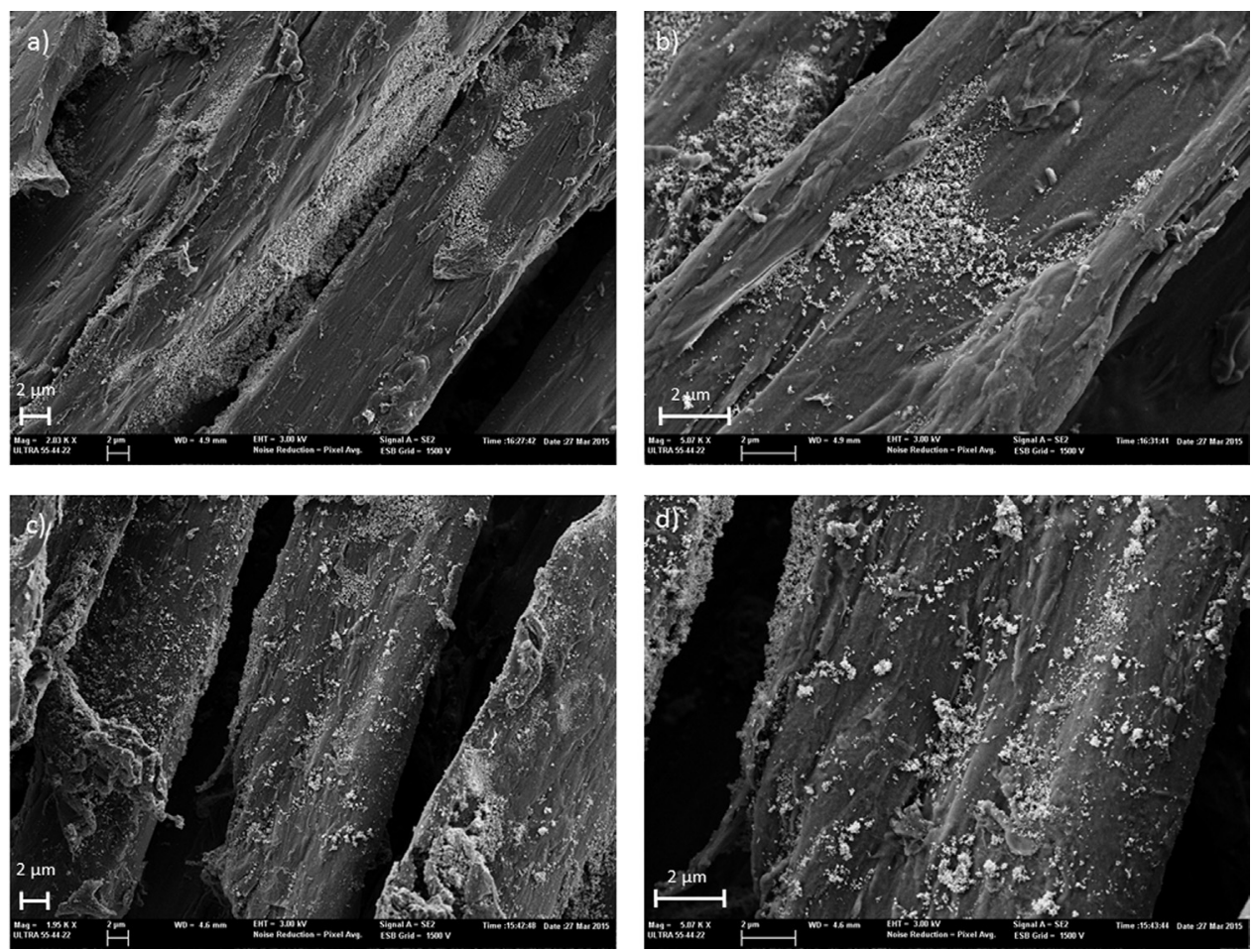

Fig. 12. FESEM micrographs of PES $-4 \mathrm{G}+\mathrm{TiO}_{2}$ prior $(\mathrm{a}, \mathrm{b})$ and after performing the photocatalytic tests (c, d). 
Table 3

Parameters of photocatalytic degradation of Rh-B solutions by PES-RGO $+\mathrm{TiO}_{2}$ samples.

\begin{tabular}{lll}
\hline Number of RGO layers & $\begin{array}{l}\text { Photocatalytic } \\
\text { efficiency, } \eta(\%)\end{array}$ & $\begin{array}{l}\text { Rate constant, } \\
K\left(\mathrm{~min}^{-1}\right)\end{array}$ \\
\hline 1 & 70.4 & $9.02 \times 10^{-2}$ \\
2 & 71.2 & $9.10 \times 10^{-2}$ \\
3 & 75.7 & $9.27 \times 10^{-2}$ \\
4 & 77.9 & $9.80 \times 10^{-2}$ \\
\hline
\end{tabular}

separation and increase its lifetime which enhances the catalytic efficiency.

\subsection{Stability of the photocatalytic fabrics}

Fig. 12 shows the micrographs of the catalytic fabrics (PES$4 \mathrm{G}+\mathrm{TiO}_{2}$ fabrics) prior (Fig. 12a, b) and after (Fig. 12c, d) performing the photocatalytic experiments. It can be seen that the major part of the $\mathrm{TiO}_{2}$ nanoparticles remain linked to the RGO structure. As mentioned in the FTIR section, the formation of a bidentate carboxylate ligand was the responsible of such stability. The same trend was observed for the rest of the fabrics (PES-1G, PES-2G and PES-3G) (Fig. S10).

Other works have reported the stability of different nanoparticles (Au nanospheres, Au nanorods, Pd nanocubes, porous Pd nanocrystals, porous $\mathrm{Pt}$ nanoparticles, Au core-Ag shell nanocuboids, Au core-Pd shell nanocuboids, and Au nanorod core-Pt shell nanostructures) on cotton fabrics [42]. The only interaction between the fabrics and the nanoparticles was the electrostatic interaction. The advantage of employing fabrics as supports for catalysis is that the catalyst can be deposited on the fabric and can be easily recovered from solution. Traditional photocatalysts that are dispersed in solution have the disadvantage that after reaction, the catalyst has to be recovered through centrifugation. The catalytic activity is affected by the recycling due to aggregation or incomplete separation from the solution [42].

More work is in progress in order to deposit $\mathrm{RGO} / \mathrm{TiO}_{2}$ composites previously synthesized on the fabrics. In this way, the nanoparticle content and contact between the components would be increased.

\section{Conclusions}

Photocatalytic fabrics have been produced by the combination of reduced graphene oxide (RGO) and $\mathrm{TiO}_{2}$ coatings on polyester fabrics. Different numbers of RGO coatings were applied (1-4) to see the influence of this parameter on the electrical, electrochemical and photocatalytic properties. FESEM, EDX and XPS showed the formation of the $\mathrm{RGO} / \mathrm{TiO}_{2}$ coatings on the fabrics. The FTIR-ATR characterization of the fabrics coated with $\mathrm{RGO}$ and $\mathrm{TiO}_{2}$ showed the apparition of a band at $1472 \mathrm{~cm}^{-1}$ attributed to a bidentate carboxylic ligand with titanium atoms. Two additional bands at $1042 \mathrm{~cm}^{-1}$ and $1172 \mathrm{~cm}^{-1}$ indicated the presence of $\mathrm{O}-\mathrm{O}$ bonds coordinated. XPS characterization showed the partial restoration of the $\mathrm{sp}^{2}$ structure after reduction due to the partial elimination of oxidized groups from the RGO structure, as the reduction of the $\mathrm{O} 1 \mathrm{~s} / \mathrm{C} 1 \mathrm{~s}$ ratio showed. No significant variations were observed between the fabrics with different number of RGO layers. It was difficult to characterize the surface $\mathrm{TiO}_{2}$ content due to the irregularity of the fabrics and the uneven distribution of the $\mathrm{TiO}_{2}$ nanoparticles. The bands observed in the FTIR-ATR spectra had a similar intensity for all the samples, which would indicate a similar $\mathrm{TiO}_{2}$ content. UV-vis diffuse reflectance technique showed an increase of the absorbance in the UV and the visible region as the number of RGO coatings increased, which would indicate a higher photocatalytic activity.
The electrical characterization by EIS showed a decrease of the impedance modulus $|Z|$ with the increasing number of RGO coatings, due to the improvement of the conducting pathways on the fabrics.

The electrochemical characterization by EIS in solution of the conductive fabrics showed an increase in the electroactivity with the number of RGO coatings. The charge transfer resistance $\left(R_{\mathrm{ct}}\right)$ and its time constant $(\tau)$ decreased, indicating a better electron transfer which could help the charge separation process to increase the lifetime of the pair electron/hole.

Scanning electrochemical microscopy (SECM) showed the changes produced by UV irradiation on the PES- $4 \mathrm{G}+\mathrm{TiO}_{2}$ fabrics. The production of photoelectrons under UV irradiation was demonstrated. Electron transfer with the redox mediator prevailed over hydroxyl reaction with the redox mediator in the conditions employed for SECM measurements (nitrogen atmosphere).

An increase in the photocatalytic degradation efficiency $(\eta)$ of Rhodamine B was observed with the increasing number of RGO layers. This increase can be attributed to a higher light absorption, better conductivity, the decrease in the charge transfer resistance $\left(R_{\mathrm{ct}}\right)$ and the decrease of the time constant $(\tau)$, which allows a better electron transfer between $\mathrm{TiO}_{2}$ nanoparticles and RGO-coated fabrics.

These fabrics could be employed as effective supports with high surface area onto which nanoparticles for photocatalytic applications can be deposited and easily recovered. The fabrics have been employed for photocatalysis in solution but they could also be applied to gas purification.

\section{Role of the founding source}

The founding sources had no any involvement in study design; in the collection, analysis and interpretation of data; in the writing of the report; and in the decision to submit the article for publication.

\section{Acknowledgements}

Authors wish to thank to the Spanish Ministerio de Ciencia e Innovación (contract CTM2011-23583) for the financial support. J. Molina is grateful to the Conselleria d'Educació, Formació i Ocupació (Generalitat Valenciana) for the Programa VALi+D Postdoctoral Fellowship. Electron Microscopy Service of the UPV (Universitat Politècnica de València) is gratefully acknowledged for help with FESEM and EDX characterization. Timothy Vickers is gratefully acknowledged for help with English revision.

\section{Appendix A. Supplementary data}

Supplementary data associated with this article can be found, in the online version, at http://dx.doi.org/10.1016/j.mseb.2015.04. 013

\section{References}

[1] R.F. Service, Science 301 (2003) 909-911.

[2] A.R. Horrocks, B.K. Kandola, P.J. Davies, S. Zhang, S.A. Padbury, Polym. Degrad. Stab. 88 (2005) 3-12

[3] M. Yu, Z. Wang, H. Liu, S. Xie, J. Wu, H. Jiang, J. Zhang, L. Li, J. Li, ACS Appl. Mater. Interfaces 5 (2013) 3697-3703.

[4] Y. Shin, D. Yoo, K. Son, J. Appl. Polym. Sci. 96 (2005) 2005-2010.

[5] A. Laforgue, J. Mater. Chem. 20 (2010) 8233-8235.

[6] R. He, T.D. Day, M. Krishnamurthi, J.R. Sparks, P.J.A. Sazio, V. Gopalan, J.V. Badding, Adv. Mater. 25 (2013) 1461-1467.

[7] D. Graham-Rowe, Nat. Photonics 1 (2007) 6-7.

[8] N.K. Vu, A. Zille, F.R. Oliveira, N. Carneiro, A.P. Souto, Plasma Process. Polym. 10 (2013) 285-296.

[9] J.O. Carneiro, V. Teixeira, J.H.O. Nascimento, J. Neves, P.B. Tavares, J. Nanosci. Nanotechnol. 11 (2011) 1-8. 
[10] J.W. Lee, T. Mayer-Gall, K. Opwis, C.E. Song, J.S. Gutmann, B. List, Science 341 (2013) 1225-1229.

[11] K.S. Novoselov, A.K. Geim, S.V. Morozov, D. Jiang, Y. Zhang, S.V. Dubonos, I.V. Grigorieva, A.A. Firsov, Science 306 (2004) 666-669.

[12] A.K. Geim, K.S. Novoselov, Nat. Mater. 6 (2007) 183-191.

[13] A.K. Geim, Science 324 (2009) 1530-1534.

[14] A.H. Castro Neto, F. Guinea, N.M.R. Peres, K.S. Novoselov, A.K. Geim, Rev. Mod. Phys. 81 (2009) 109-162.

[15] H.B. Heersche, P. Jarillo-Herrero, J.B. Oostinga, L.M.K. Vandersypen, A.F. Morpurgo, Nature 446 (2007) 56-59.

[16] M.J. Allen, V.C. Tung, R.B. Kaner, Chem. Rev. 110 (2010) 132-145.

[17] C. Soldano, A. Mahmood, E. Dujardin, Carbon 48 (2010) 2127-2150.

[18] V. Singh, D. Joung, L. Zhai, S. Das, S.I. Khondaker, S. Seal, Prog. Mater. Sci. 56 (2011) 1178-1271.

[19] S. Morales-Torres, L.M. Pastrana-Martínez, J.L. Figueiredo, J.L. Faria, A.M.T. Silva, Environ. Sci. Pollut. Res. 19 (2012) 3676-3687.

[20] L.-L. Tan, S.-P. Chai, A.R. Mohamed, ChemSusChem 5 (2012) 1868-1882.

[21] R. Leary, A. Westwood, Carbon 49 (2011) 741-772.

[22] N. Zhang, Y. Zhang, Y.-J. Xu, Nanoscale 4 (2012) 5792-5813.

[23] V. Štengl, S. Bakardjieva, T.M. Grygar, J. Bludská, M. Kormunda, Chem. Cent. J. 7 (2013) 41.

[24] J. Liu, H. Bai, Y. Wang, Z. Liu, X. Zhang, D.D. Sun, Adv. Funct. Mater. 20 (2010) $4175-4181$.

[25] E. Lee, J.-Y. Hong, H. Kang, J. Jang, J. Hazard. Mater. 219-220 (2012) 13-20.

[26] P. Fernández-Ibáñez, M.I. Polo-López, S. Malato, S. Wadhwa, J.W.J. Hamilton, P.S.M. Dunlop, R. D’Sa, E. Magee, K. O’Shea, D.D. Dionysiou, J.A. Byrne, Chem. Eng. J. 261 (2015) 36-44.

[27] L.-L. Tan, W.-J. Ong, S.-P. Chai, A.R. Mohamed, Nanoscale Res. Lett. 8 (2013) 465.

[28] V.H. Nguyen, J.J. Shim, Mater. Sci. Eng. B 180 (2014) 38-45.

[29] H. Sun, S. Liu, S. Liu, S. Wang, Appl. Catal. B: Environ. 146 (2014) 162-168.

[30] G. Williams, B. Seger, P.V. Kamat, ACS Nano 7 (2008) 1487-1491.

[31] H. Kim, G. Moon, D. Monllor-Satoca, Y. Park, W. Choi, J. Phys. Chem. C 116 (2012) $1535-1543$.

[32] B. Jiang, C. Tian, Q. Pan, Z. Jiang, J.-Q. Wang, W. Yan, H. Fu, J. Phys. Chem. C 115 (2011) 23718-23725

[33] J.S. Lee, K.H. You, C.B. Park, Adv. Mater. 24 (2012) 1084-1088.

[34] H.-C. Hsu, I. Shown, H.-Y. Wei, Y.-C. Chang, H.-Y. Du, Y.-G. Lin, C.-A. Tseng, C.-H. Wang, L.-C. Chen, Y.-C. Lind, K.-H. Chen, Nanoscale 5 (2013) 262-268.

[35] T.-F. Yeh, J. Cihlář, C.-Y. Chang, C. Cheng, H. Teng, Mater. Today 16 (2013) 78-84.

[36] K. Krishnamoorthy, R. Mohan, S.-J. Kim, Appl. Phys. Lett. 98 (2011) 244101.

[37] Y. Zhang, Z.-R. Tang, X. Fu, Y.-J. Xu, ACS Nano 4 (2010) 7303-7314.

[38] N. Zhang, M.-Q. Yang, Z.-R. Tang, Y.-J. Xu, ACS Nano 8 (2014) 623-633.

[39] M.-Q. Yang, N. Zhang, M. Pagliaro, Y.-J. Xu, Chem. Soc. Rev. 43 (2014) $8240-8254$.

[40] C. Han, M.-Q. Yang, N. Zhangab, Y.-J. Xu, J. Mater. Chem. A 2 (2014) $19156-19166$.

[41] S. Liu, B. Weng, Z.-R. Tang, Y.-J. Xu, Nanoscale 7 (2015) 861-866.

[42] B. Yang, C. Zhao, M. Xiao, F. Wang, C. Li, J. Wang, J.C. Yu, Small 9 (2013) 1003-1007.

[43] D. Wu, M. Long, J. Zhou, W. Cai, X. Zhu, C. Chen, Y. Wu, Surf. Coat. Technol. 203 (2009) 3728-3733.

[44] J. Kiwi, C. Pulgarin, Catal. Today 151 (2010) 2-7.
[45] M.I. Mejía, J.M. Marín, G. Restrepo, C. Pulgarín, E. Mielczarski, J. Mielczarski, Y. Arroyo, J.-C. Lavanchy, J. Kiwi, Appl. Catal. B: Environ. 91 (2009) 481-488.

[46] M.J. Uddin, F. Cesano, D. Scarano, F. Bonino, G. Agostini, G. Spoto, S. Bordiga, A. Zecchina, J. Photochem. Photobiol. A 199 (2008) 64-72.

[47] T. Yuranova, R. Mosteo, J. Bandara, D. Laub, J. Kiwi, J. Mol. Catal. A: Chem. 244 (2006) 160-167.

[48] D. Wu, M. Long, Surf. Coat. Technol. 206 (2011) 1175-1179.

[49] L. Karimi, M.E. Yazdanshenas, R. Khajavi, A. Rashidi, M. Mirjalili, Appl. Surf. Sci. 332 (2015) 665-673.

[50] L. Karimi, M.E. Yazdanshenas, R. Khajavi, A. Rashidi, M. Mirjalili, Cellulose 21 (2014) 3813-3827.

[51] J. Molina, J. Fernández, M. Fernandes, A.P. Souto, M.F. Esteves, J. Bonastre, F. Cases, Synth. Met. 202 (2015) 110-122.

[52] Complete Textile Glossary, 2001, Available from: http://www.composites. ugent.be/home_made_composites/documentation/Illustrated_dictionary_of_ fiber_and_textile_technology.pdf (accessed 19.01.15).

[53] N. Carneiro, A.P., Souto, F., Forster, E. Prinz, Patent in internationalization phase (2004)/patent number PCT/PT2004/000008 (2004).

[54] J. Molina, F.R. Oliveira, A.P. Souto, M.F. Esteves, J. Bonastre, F. Cases, J. Appl. Polym. Sci. 129 (2013) 422-433.

[55] Y.J. Yun, W.G. Hong, W.-J. Kim, Y. Jun, B.H. Kim, Adv. Mater. 25 (2013) 5701-5705.

[56] B. Fugetsu, E. Sano, H. Yu, K. Mori, T. Tanaka, Carbon 48 (2010) 3340-3345.

[57] X. Shen, X. Lin, N. Yousefi, J. Jia, J.-K. Kim, Carbon 66 (2014) 84-92.

[58] G.G. Wallace, R.B. Kaner, M. Muller, S. Gilje, D. Li, Nat. Nanotechnol. 3 (2008) $101-105$.

[59] M.-J. Li, C.-M. Li, Y.-B. Xie, H.-B. Cao, H. Zhao, Y. Zhang, Carbon 66 (2014) $302-311$.

[60] J.O. Carneiro, S. Azevedo, F. Fernandes, E. Freitas, M. Pereira, C.J. Tavares, S. Lanceros-Méndez, V. Teixeira, J. Mater. Sci. 49 (2014) 7476-7488.

[61] F. Bei, X. Hou, S.L.Y. Chang, G.P. Simon, D. Li, Chem. Eur. J. 17 (2011) 5958-5964

[62] J. Molina, J. Fernández, J.C. Inés, A.I. del Río, J. Bonastre, F. Cases, Electrochim. Acta 93 (2013) 44-52.

[63] J. Molina, J. Fernández, A.I. del Río, J. Bonastre, F. Cases, Appl. Surf. Sci. 279 (2013) 46-54.

[64] K.-S. Tseng, Y.-L. Lo, Opt. Mater. Express 4 (2014) 764-775.

[65] J. Molina, A. Zille, J. Fernández, A.P. Souto, J. Bonastre, F. Cases, Synth. Met. 204 (2015) 110-121.

[66] J.C. Yu, L. Zhang, J. Yu, New J. Chem. 26 (2002) 416-420.

[67] Y. Vakhula, K. Besaha, I. Lutsyuk, Chem. Chem. Technol. 6 (2012) 431-434

[68] D. Yang, A. Velamakanni, G. Bozoklu, S. Park, M. Stoller, R.D. Piner, S. Stankovich, I. Jung, D.A. Field, C.A. Ventrice Jr., R.S. Ruoff, Carbon 47 (2009) 145-152.

[69] B. Erdem, R.A. Hunsicker, G.W. Simmons, E.D. Sudol, V.L. Dimonie, M.S. ElAasser, Langmuir 17 (2001) 2664-2669.

[70] D.R. Dreyer, S. Park, C.W. Bielawski, R.S. Ruoff, Chem. Soc. Rev. 39 (2010) $228-240$.

[71] E. Casero, A.M. Parra-Alfambra, M.D. Petit-Domínguez, F. Pariente, E. Lorenzo, C. Alonso, Electrochem. Commun. 20 (2012) 63-66.

[72] P. Sun, F.O. Laforge, M.V. Mirkin, Phys. Chem. Chem. Phys. 9 (2007) 802-823.

[73] L. Rajendran, S.P. Ananthi, J. Electroanal. Chem. 561 (2004) 113-118.

[74] H. Maeda, K. Ikeda, K. Hashimoto, K. Ajito, M. Morita, A. Fujishima, J. Phys. Chem. B 103 (1999) 3213-3217. 